Article

\title{
Impact of Control System Model Parameters on the Obstacle Avoidance by an Autonomous Car-Trailer Unit: Research Results
}

\author{
Leon Prochowski ${ }^{1,2}$, Mateusz Ziubiński ${ }^{1, * \mathbb{D}}$, Patryk Szwajkowski ${ }^{3} \mathbb{D}$, Mirosław Gidlewski $^{1,2}{ }^{\text {, Tomasz Pusty }}{ }^{4}$ \\ and Tomasz Lech Stańczyk ${ }^{5}$
}

1 Institute of Vehicles and Transportation, Military University of Technology (WAT), gen. Sylwestra Kaliskiego 2 Street, 00-908 Warsaw, Poland; leon.prochowski@wat.edu.pl (L.P.); miroslaw.gidlewski@wat.edu.pl (M.G.)

2 Łukasiewicz Research Network-Automotive Industry Institute (Łukasiewicz-PIMOT), Jagiellońska 55 Street, 03-301 Warsaw, Poland

3 Electromobility Department, Łukasiewicz Research Network-Automotive Industry Institute (Łukasiewicz-PIMOT), Jagiellońska 55 Street, 03-301 Warsaw, Poland; patryk.szwajkowski@pimot.lukasiewicz.gov.pl

4 Vehicle Tests Laboratory, Łukasiewicz Research Network-Automotive Industry Institute (Łukasiewicz-PIMOT), Jagiellońska 55 Street, 03-301 Warsaw, Poland; tomasz.pusty@pimot.lukasiewicz.gov.pl

5 Department of Automotive Engineering and Transport, Kielce University of Technology, Ave. 1000—lecia Państwa Polskiego 7, 25-314 Kielce, Poland; stanczyk@tu.kielce.pl

* Correspondence: mateusz.ziubinski@wat.edu.pl

check for updates

Citation: Prochowski, L.; Ziubiński, M.; Szwajkowski, P.; Gidlewski, M.; Pusty, T.; Stańczyk, T.L. Impact of Control System Model Parameters on the Obstacle Avoidance by an Autonomous Car-Trailer Unit: Research Results. Energies 2021, 14, 2958. https://doi.org/10.3390/ en14102958

Academic Editor: Islam Safak Bayram

Received: 2 April 2021

Accepted: 17 May 2021

Published: 20 May 2021

Publisher's Note: MDPI stays neutral with regard to jurisdictional claims in published maps and institutional affiliations.

Copyright: (c) 2021 by the authors. Licensee MDPI, Basel, Switzerland. This article is an open access article distributed under the terms and conditions of the Creative Commons Attribution (CC BY) license (https:/ / creativecommons.org/licenses/by/ $4.0 /)$.

\begin{abstract}
The introduction of autonomous cars will help to improve road traffic safety, and the use of a cargo trailer improves the energy efficiency of transport. One of the critical (collision) road situations has been considered, where immediate counteraction is required in a space that has been only partly defined. This research work was aimed at determining the impact of the trajectory planning method and the values of some parameters of the control system on the feasibility of safe avoidance of an obstacle that has suddenly appeared. The obstacle is assumed to be a motor vehicle moving on a road intersection along a collision path in relation to the autonomous car-trailer unit (CT unit) travelling at high speed. Analysis of cooperation between several non-linear models (representing the car, trailer, tyre-road interaction, and driving controller) has been carried out. Mathematical models of the control system and the CT unit have been built. The process of selection of temporary and variable parameters, applied to the control system for the time of the critical situation under consideration, has been shown. The research work carried out has made it possible to recommend appropriate parameter values for the control system.
\end{abstract}

Keywords: safety of autonomous motor vehicle; autonomous motor vehicle with a trailer; critical road situations; vehicle trajectory planning; mathematical modelling motor vehicle with a trailer; control system of an autonomous motor vehicle

\section{Introduction}

Autonomous vehicles are considered as a solution expected to improve the efficiency of transport processes. An important good point of the introduction of autonomous vehicles will be an improvement in road traffic safety. Such an effect, however, will not be produced automatically. It may be achieved through research on vehicle behaviour, including the selection of a vehicle controlling method that would be adequate for difficult road situations. The problem of adapting the vehicle control process to special road situations has been raised, e.g., in [1-7]. A key factor is here the programming of the vehicle control system, in which the algorithms responsible for planning the obstacle-avoiding trajectories are of significant importance. At present, the research works on the control systems are predominantly focused on the planning of vehicle trajectories for lane-change maneuvers (obstacle avoiding, overtaking) [6,8-11]. 
A lane-change maneuver of this kind is usually planned in advance and performed in predictable conditions, where the restrictions arising from the necessity of avoiding collisions with other vehicles participating in the traffic or from the kinematic and dynamic properties of the vehicle in question can be easily met. In such a situation, a planning stage can be introduced to the control system, at which time the appropriate trajectory would be chosen from a library of solutions pre-programmed in the system controller [12].

The addition of a trailer to the autonomous vehicle will result in better economic and energy efficiency of the transport processes. However, this will also bring about a change in the dynamic properties of the CT unit compared with those of the motor vehicle alone. The presence of a trailer radically affects the dynamics of the towing vehicle and reduces the stability of the vehicle combination as a whole. An extensive review of such research works on CT units has been presented in $[13,14]$. The attaching of a trailer to a motor vehicle may also cause oscillations of the CT unit in the final phase of the obstacle avoidance process (in the initial phase, the trajectories of both vehicles are almost identical). This can be observed, e.g., in the profile of the trajectory of the CT unit's center of gravity (CG) for rising vehicles' yaw angles from the carriageway centerline [15]. The research on the stability of CT unit's motion, reported in [13,14], has shown that the instabilities occurring in the trailer and vehicle's motion strongly depend on the mass and moment of inertia of the vehicles and on the drawbar length. Experimental research on the stability of a car-trailer unit within a sped range of $48-90 \mathrm{~km} / \mathrm{h}$, with a rapid turn of the steering wheel, has confirmed decisive impact of the parameters mentioned above on the behaviour of the vehicle combination [16]. These findings have been taken into account in the modelling described hereafter. The controlling of a motorcar-trailer unit is a far more complex issue in comparison with the controlling of a motor vehicle alone [15]. The values and ranges of the input parameters applied to the control system model must be different as well.

The participation of autonomous motor vehicles in the road traffic may be described with using a few elementary vehicle trajectory models: following of the preceding vehicle, following-up of predesigned reference models, and driving to follow up models that would represent the planned (theoretical) vehicle trajectory $[5,6,17]$. The design of such models is based on analyses of specific traffic situations and the most frequent drivers behaviors $[18,19]$. This is of critical importance for the safe operation of autonomous vehicles in the road traffic where cars driven by human drivers will remain predominate for many upcoming years.

Regardless of the driving model chosen, autonomous vehicles move to follow up a preplanned trajectory. This is also the case when the obstacle avoidance takes place. A critical review of the trajectory planning methods has been presented, e.g., in $[1,11]$. The trajectory planning is based on determining the curve that describes the lateral displacement of the center of vehicle mass (e.g., when the vehicle changes the lane to the adjacent one) in the form of algebraic equations, which may represent sequences of circular arcs, polynomial splines, clothoid splines, Bézier curves, etc. $[1,5,9,20]$. When the desired vehicle trajectory is determined, it is important that the basic limitations dictated by the properties of real cars and road surface should be taken into account [21]. As an example, a method of generating the vehicle trajectory has been presented in [8], where the maximum acceptable values of the lateral (centripetal) acceleration of the car were taken into account. In the work reported in [9], the vehicle trajectories and their curvatures were planned taking into account the comfort of vehicle occupants, e.g., a requirement was adopted that the lateral acceleration should not exceed $1.6 \mathrm{~m} / \mathrm{s}^{2}$ (the limit for good comfort) or $3.6 \mathrm{~m} / \mathrm{s}^{2}$ (the limit for medium occupant's comfort). In the vehicle control system, calculations are carried out to plan the desired vehicle trajectory and to track the actual one. As another option, a controller provided with a library of pre-programmed solutions suitable for plannable situations may be used [12]. An example of planning a trajectory for a safe lane-change and obstacle avoidance maneuver, taking into account the current traffic situation and the dynamic properties of the CT unit, is shown in [10]. In the vehicle control process, the goal is to minimize the distance between the current position of the center of vehicle mass 
and the planned vehicle trajectory, and to minimize the difference between the angular positions of the longitudinal vehicle axis and the tangent to the said trajectory [22-24].

In this role, PID (proportional-integral-derivative) controllers and controllers based on fuzzy logic predominate. As an example: in $[20,24]$, the control process is based on the follow-up of the preset vehicle trajectory by a PID controller and the effective use of fuzzy logic in the controllers of mobile robots and vehicles is shown in $[18,23,25]$. A good result of controlling the drive of mobile platforms in [21] was achieved by using two different control techniques. The controlling of a car with a trailer in typical road situations has been analyzed in [10], where the current obstacle position and the static space limitations posed by the road infrastructure have been taken into account. An interesting method of planning the vehicle trajectory, taking into account the field of "obstacle repulsion" potential during the lane-change maneuver, has been proposed in [6]. In [26], on the other hand, the trajectory was planned based on the preset direction of vehicle movement and the positions of the centers of front and rear axles of an articulated wheel loader relative to the optimum trajectory. The motion of such a machine in a predetermined environment has been described by a trajectory composed of circular arcs and line segments.

At present, the vehicle trajectory is predominantly planned on the grounds of the limitations dictated by the structural vehicle's properties [7,27], and the basic vehicle control methods include the fuzzy logic algorithms [11,27].

Most of the reported methods of generating the desired vehicle trajectory apply to typical maneuvers often performed in road traffic. In contrast, there is a lack of research works and models applicable to the critical situations where autonomous vehicles towing trailers with a high speed would be involved. Particularly dangerous situations take place when the vehicle and the obstacle move along collision paths and in an environment that has been only partly defined.

The study presented includes an analysis of the problem of avoiding an obstacle in a critical road situation that may arise from, e.g., another vehicle driver's failure to yield the right of way on a road intersection. This usually develops into front-to-side collisions of moving vehicles; the percentage of such collisions in the total number of road accidents in Poland shows an upward trend. At present, the said percentage amounts to 32\% [28].

It is peculiar to the critical situations that they require difficult defensive (accidentavoiding) maneuvers to be performed, which are often based on very aggressive vehicle control. If this is the case, the vehicle trajectory is planned without being impeded by any limitations related to the possible occurrence of excessive lateral acceleration, tire sideslip, or development of forces exceeding the lateral tire-road adhesion. The analysis applies to a road situation where immediate counteraction is required in a space that has been only partly defined. The autonomous vehicle's control system is expected to plan a safe vehicle trajectory based on information received from an environment perception system. It has been assumed that the algorithm of controlling the vehicle will not change in spite of the occurrence of a critical situation. Nevertheless, the following factors may change according to the information received from the environment perception system:

- vehicle trajectories planning (calculation) method;

- values of the parameters that are treated as variables in the vehicle control algorithm during the obstacle avoidance maneuvers.

Therefore, a temporary trajectory is planned in the critical situation under analysis in order to avoid a collision with the obstacle.

The objective of this study is to determine the impact of the trajectory planning method and of the values of some control system parameters on the feasibility of the safe avoidance of an obstacle having suddenly appeared. In this study, the obstacle is a motor vehicle whose driver has violated traffic regulations. The obstacle is moving on a road intersection with poor visibility along a collision path in relation to an autonomous CT unit travelling with a high speed (Figure 1). After hard braking, the said motor vehicle has stopped with blocking one lane for the $\mathrm{CT}$ unit. A trajectory planning method and desirable values of the temporary parameters of the control system, which is based on an anticipating model and 
fuzzy logic, will be shown. The areas of advantageous choice of the temporary parameter values for the critical situation under analysis will be indicated. The problem is explored using computer simulation based on a model of CT unit's dynamics in curvilinear motion. The model was subjected to a validation process, in which results of experimental tests of dynamic lane changing by the CT unit were used.
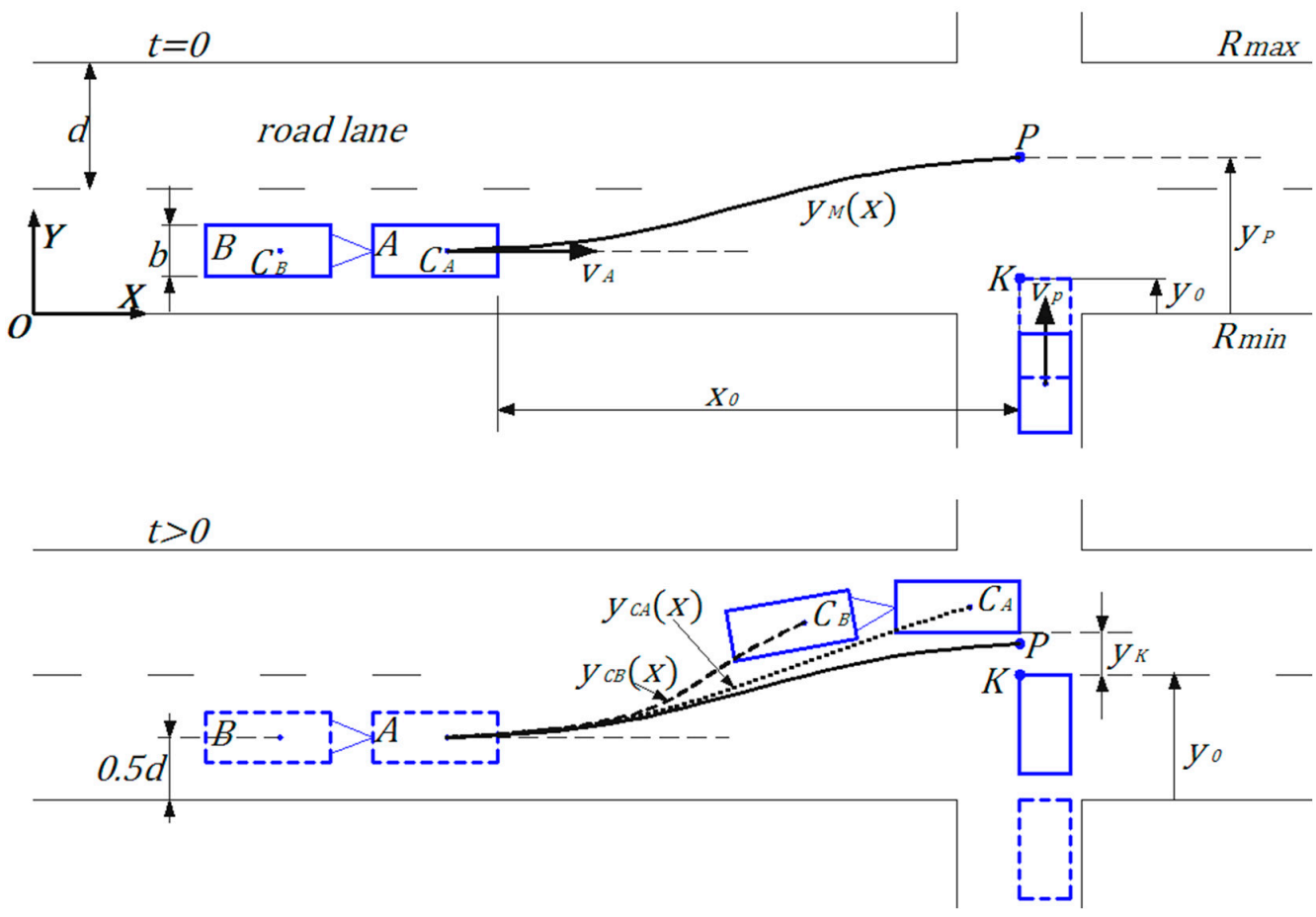

Figure 1. Road situation under analysis.

In this study, a situation is analyzed in which the vehicle's environment perception system has detected an obstacle that suddenly appeared at a distance that may be shorter than the stopping distance of the autonomous vehicle with a trailer. For such a situation, an assumption has been made that the information received from the environment perception system will cause the settings of the control system of the CT unit to be adjusted as appropriate. The new settings will be introduced temporarily (only for the time of avoiding the obstacle) and their values will differ from those required at the stable vehicle drive before and after the obstacle avoidance maneuver. The necessity of local trajectory planning in critical situations has been pointed out, e.g., in [29], where the limitations additionally arising from excessive tire slip and from development of forces exceeding the lateral tire-road adhesion have been highlighted.

In this problem, the control system must cope with a very difficult task. This is not only due to the very short time available for the perception of a specific road situation and for the trajectory planning, but also because of the dilemmas that would arise from the possible lack of any non-collision solution. Such a sudden situation, where only very few of the practicable defensive maneuvers may result in the successful avoidance of a road accident, may be defined as a critical one.

The behavior of a CT unit on the $0-60 \mathrm{~m}$ road section under analysis, i.e., before and beyond the obstacle, has been analyzed in [2]. In particular, the trajectory of the center of mass of the vehicle combination has been examined. The analysis presented herein is more detailed and the motion of outermost points on the external edges of the vehicle and trailer has been observed. Simultaneously, the analysis has been reduced to a $0-30 \mathrm{~m}$ road section, i.e., to the situation before the point where a collision between the vehicles involved may occur. 


\section{Scenario of the Road Situation under Analysis}

In this study, the motion of the combination of an autonomous motorcar with a cargo trailer (CT unit) on two lines road with right of way is analyzed. During the motion, the vehicle's perception system has just detected the sudden appearance of another vehicle moving along a collision path (Figure 1). The said other vehicle may be expected to block within a short time the whole width of the lane used by the $\mathrm{CT}$ unit and thus to become an obstacle for the latter.

The following notation will be used in this study:

$A, B$-autonomous motorcar and trailer, respectively of center of mass $C_{A}, C_{B}$;

$R_{\min }, R_{\max }$-symbols indicating the outermost edges of the lanes involved;

$L_{a}$-anticipation radius, used when trajectory $y_{T}(x)$ is generated;

$y_{M}(x), y_{T}(x)$ - planned and preset vehicle trajectory;

$y_{0}$-instantaneous obstacle position in relation to lane edge $R_{\min }$;

$y_{C A}(x), y_{C B}(x)$-trajectories of the centers of mass of vehicles $A$ and $B$;

$K, P$-characteristic points: trace of the obstacle edge and target point for the planning of a safe trajectory $y_{M}(x)$;

$y_{W}$-clearance margin, necessary for safe obstacle avoidance;

$y_{K}$-clearance between the vehicle and the obstacle at the instant when the latter is being passed by;

$b, d$-widths of the vehicle combination (CT unit) and the lane;

$\delta_{H}, \delta, \alpha, \beta$-steering wheel angle, steering angle, tire sideslip angle, and angle of position of the tangent to the planned or preset trajectory of the vehicles;

$R_{0}, \kappa$-radius and curvature of the vehicle trajectory;

$\omega_{u} ; v_{T u}=\omega_{u} r_{D u}$-angular velocity of the $u$ th vehicle wheel and circumferential velocity of the tyre;

$r_{D u}$-dynamic tire radius of the $u$ th vehicle wheel;

$v, v_{A}$-velocity of the center of mass of vehicle $A$;

$\Delta \psi=\psi_{A}-\psi_{B}$-trailer drawbar turning angle;

$\psi_{A}, \psi_{B}$-yaw angles of the motor vehicle and the trailer;

$F_{Q}, a_{y}$-centrifugal inertia force and lateral acceleration of center of mass of the vehicle body.

The OXY coordinate system is attached to the $R_{\min }$ lane edge.

\section{Control System and Model of Dynamics of the Vehicles}

\subsection{Structure of the Autonomous Vehicle's Control System}

The CT unit's motion results from the cooperation of the following three major system components:

- environment perception system;

- vehicle control system;

- model adopted to represent the dynamics of the vehicle combination (CT unit).

The cooperation of the above system components has been illustrated in Figure 2.

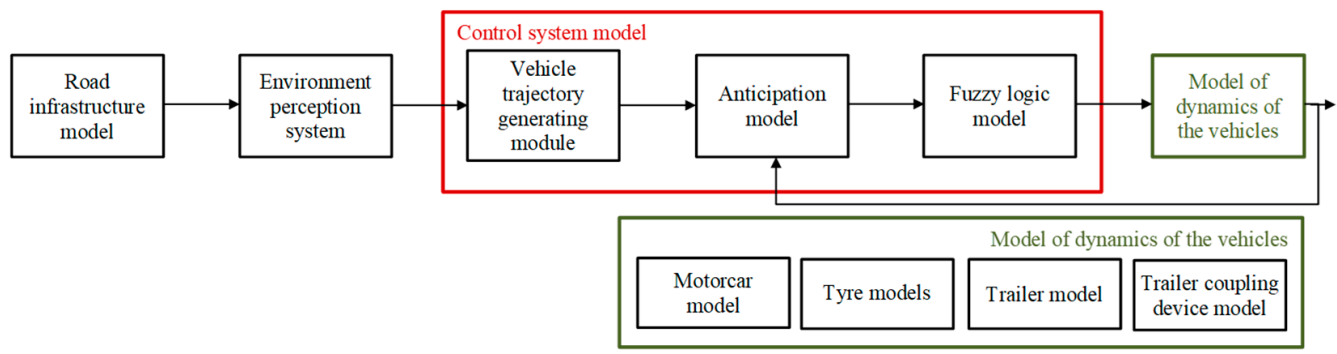

Figure 2. Structure of the control system. 


\subsection{Procedure of Determining the Control Signal Using a Fuzzy Logic Model}

The sudden intrusion of an obstacle onto the lane used by the autonomous vehicle, as analyzed herein, means that an obstacle $\left(y_{0}>0\right)$ appears at a distance of $x_{0}$ ahead of the vehicle (Figure 1). A case is addressed where this distance may be shorter than the stopping distance $S_{Z}$ for the CT unit. Then, a safe solution may be to avoid the obstacle with using the adjacent road lane. In such a case, the method detecting the obstacle edge $K$ by the environment perception system is very effective [30]. Based on an analysis of the current position of edge $K$ relative to the $R_{\min }$ lane edge, the predicted position of the target point $P$ (Figure 1), i.e., the $y_{P}$ value, is calculated from Equation (1):

$$
y_{P}=y_{0}+0.5 b+y_{W}
$$

This makes it possible to calculate trajectory $y_{M}(x)$ in the control system (Figure 3 ); the trajectory is treated as the desired (planned) path of the center of mass $C_{A}$ within the $x_{0}$ road section [3]. The selection of an algorithm to generate this trajectory has been described in a subsequent part of this paper. The said trajectory is applied as an input to the anticipating model, where trajectory $y_{T}(x)$ is calculated based on equations:

$$
\begin{gathered}
y_{T}(x)=0.5 d \text { for } x \in\left\langle 0 ; L_{a}\right) \\
y_{T}(x)=y_{M}\left(\frac{x-L_{a}}{x_{0}-L_{a}} x\right) \text { for } x \in\left\langle L_{a} ; x_{0}\right) \\
y_{T}(x)=y_{0} \text { for } x=x_{0}
\end{gathered}
$$

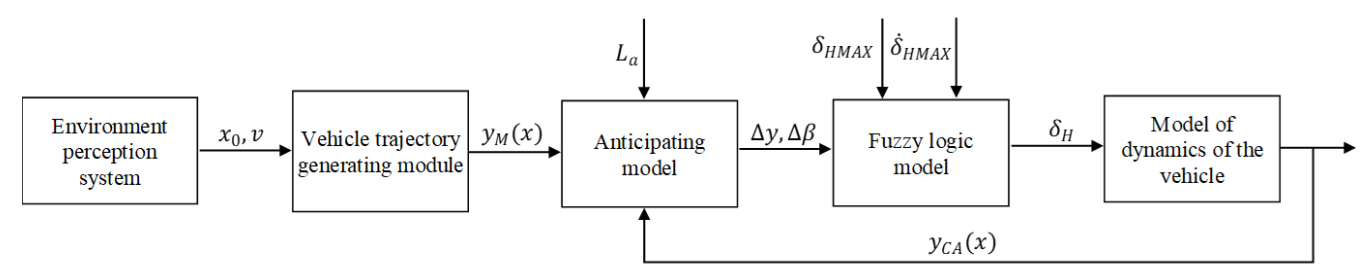

Figure 3. Schematic diagram of the processing of trajectory $y_{M}(x)$ in order to determine the steering wheel angle $\delta_{H}$ settings.

In Equation (2), the properties of the anticipating model and the value of the anticipation radius $L_{a}$ are made use of. The determination of the anticipation radius value, together with the method of planning the vehicle trajectory for the critical situation under analysis, has been presented in Section 6. Trajectory $y_{T}(x)$ and path $y_{C A}(x)$ of the center of mass of the motor vehicle make a basis for determining the $\Delta y$ and $\Delta \beta$ values.

The $\Delta y$ and $\Delta \beta$ values describe the divergence between the trajectory planned and the actual vehicle path. They have been shown in Figure 4:

$$
\begin{aligned}
\Delta y & =y_{T}(x)-y_{C A}(x) \\
\Delta \beta & =\beta_{T}(x)-\beta_{C A}(x)
\end{aligned}
$$

The fuzzy logic model used in the control system minimizes the $\Delta y$ and $\Delta \beta$ values by immediate and ongoing adjustment of the steering wheel angle $\delta_{H}$ in the model of vehicle dynamics. The fuzzy logic model is shown in Figure 5. It represents the connection between the input signals $\left(\Delta y\right.$ and $\Delta \beta$ ) and the steering wheel angle values $\delta_{H}$ necessary for the obstacle to be avoided. The model includes inference rules based on associating the input signal values with possible logic states of these parameters. The inference rules are based on functions with trapezoidal profiles. In the model, the limit values of the input signals have been adopted as limitations $\delta_{H M A X}$ and $\dot{\delta}_{H M A X}$, determined by motor vehicle construction. To pass from the logic value of the input signal to the resultant value of the steering wheel angle $\delta_{H}$, the analytical centrode model was used. 


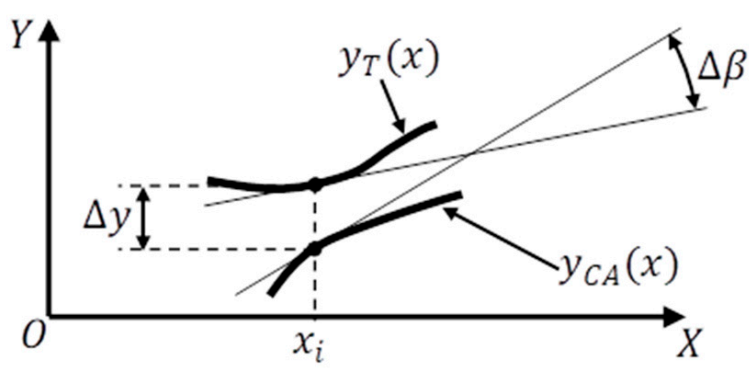

Figure 4. Illustration for determining $\Delta y$ and $\Delta \beta$ based on the course of the $y_{T}(x)$ and $y_{C A}(x)$ curves at point $x_{i}$.

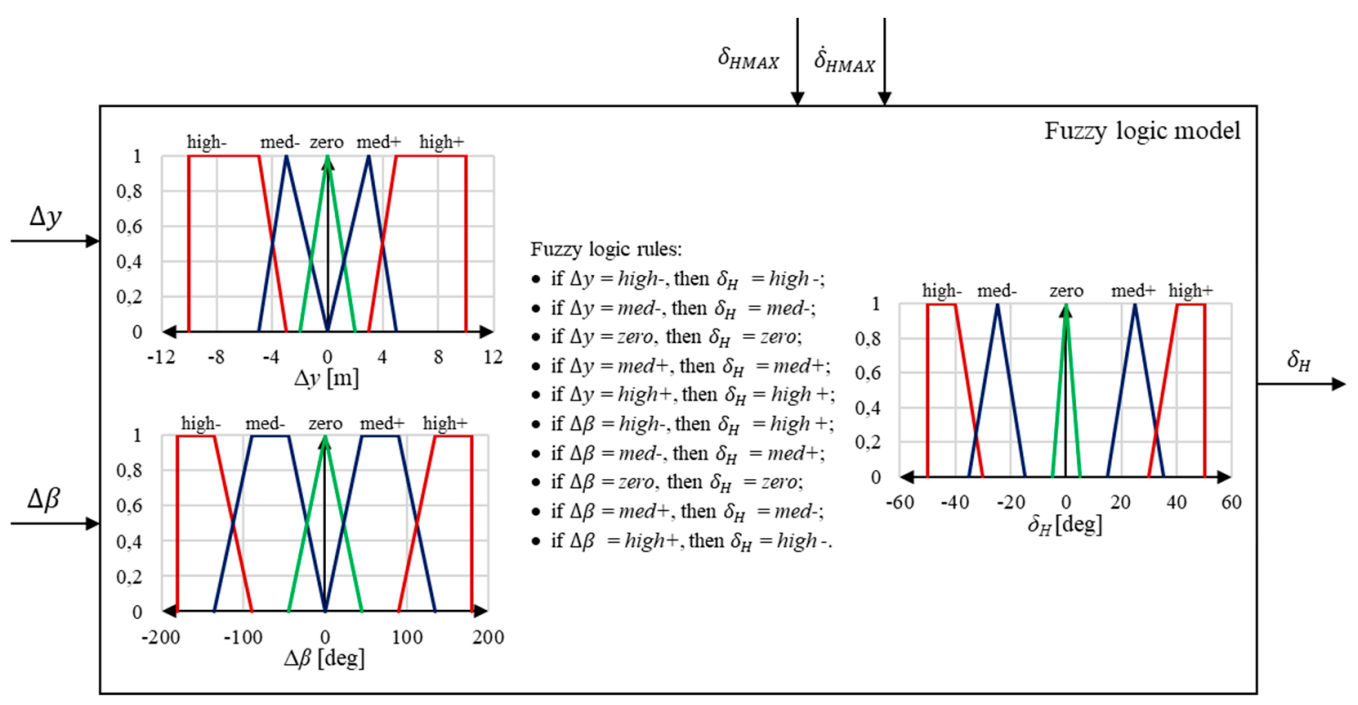

Figure 5. Structure of the fuzzy logic model used.

\subsection{Model of Dynamics of the CT Unit}

\subsubsection{Generalized Coordinates; Equations of Motion of the CT Unit}

The model of a CT unit is shown in Figure 6. It is generated in the PC-CRASH computer program, which is used to model the movement of vehicles in collision situations [31,32]. To describe and analyze the CT unit's motion, global and local coordinate systems have been used, pursuant to ISO 8855:

- $\quad O X Y Z$-Cartesian coordinate system $\{O\}$, attached to the road infrastructure;

- $C_{S} X_{S} Y_{S} Z_{S}$-local coordinate systems $\left\{C_{S}\right\}$, with their origins at the centres of mass of vehicle bodies; $\{s\}=[A, B]$;

- $O_{T u} x_{T u} y_{T u} z_{T u}$-local coordinate systems $\left\{O_{T u}\right\}$, each having its origin at the centre of the tyre-road contact area of the $u$ th wheel $(u=1,2, \ldots, 6 ; 4$ vehicle wheels and 2 trailer wheels, the latter being assumed as twin wheels).

The vehicle bodies are solid with 6 degrees of freedom. Each of the wheels has a degree of freedom related to its rotational motion, which means that it has a moment of inertia relative to the axis of wheel rotation. Road wheels are linked with vehicle bodies by spring and damping elements with non-linear characteristics. They can move parallel to the $C_{S} Z_{s}$ axis relative to the vehicle body. 


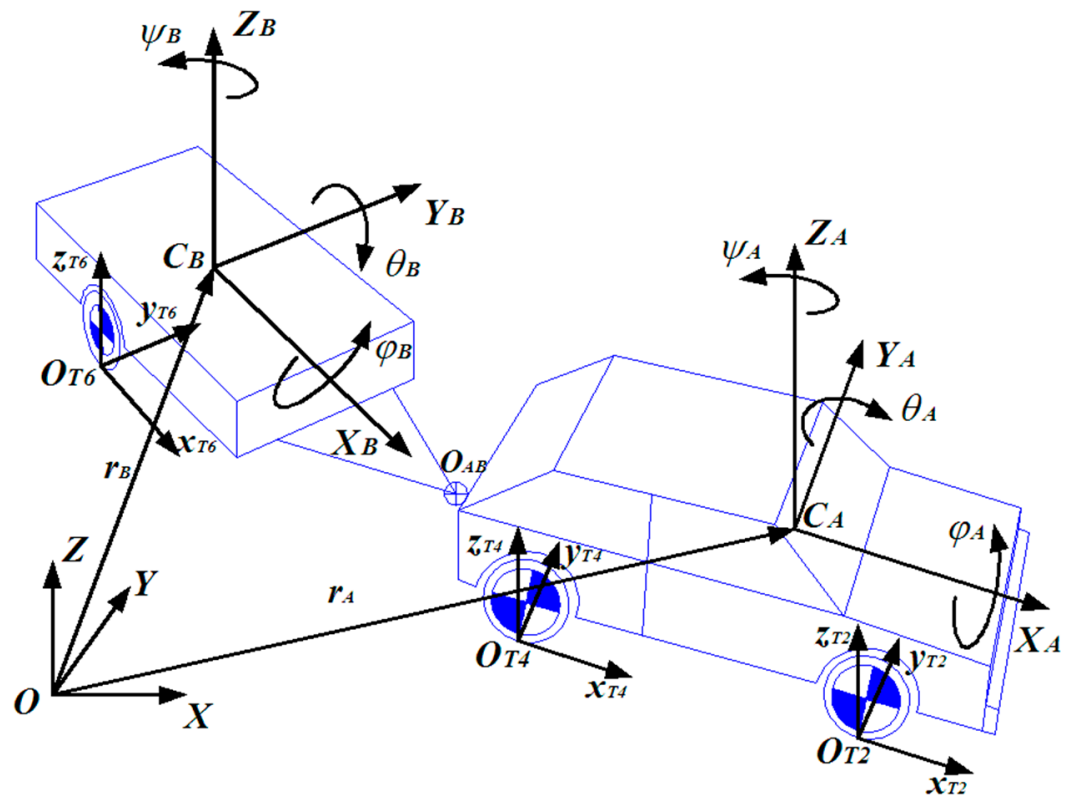

Figure 6. Model of a CT unit and the coordinate systems.

The interdependences between the coordinate systems may be described as follows:

$$
\left[\begin{array}{l}
X \\
Y \\
Z
\end{array}\right]=N_{O C S}\left[\begin{array}{l}
X_{S} \\
Y_{S} \\
Z_{S}
\end{array}\right]
$$

(global system $\{O\}$ vs. local system $\left\{C_{s}\right\}$ as defined above)

$$
N_{O C S}=\left[\begin{array}{ccc}
\cos \psi_{s} \cos \theta_{s} & \cos \psi_{s} \sin \theta_{s} \sin \varphi_{s}-\sin \psi_{s} \cos \varphi_{s} & \cos \psi_{s} \sin \theta_{s} \cos \varphi_{s}+\sin \psi_{s} \sin \varphi_{s} \\
\sin \psi_{s} \cos \theta_{s} & \sin \psi_{s} \sin \theta_{s} \sin \varphi_{s}+\cos \psi_{s} \cos \varphi_{s} & \sin \psi_{s} \sin \theta_{s} \cos \varphi_{s}-\cos \psi_{s} \sin \varphi_{s} \\
-\sin \theta_{s} & \cos \theta_{s} \sin \varphi_{s} & \cos \theta_{s} \cos \varphi_{s}
\end{array}\right]
$$

where:

$\psi_{s}, \theta_{s}, \varphi_{s}$ - quasi-Euler angles, defining the orientation of the local system $\left\{C_{s}\right\}$ relative to the global system $\{O\}$, i.e.:

$\psi_{s}$ - yaw angle;

$\theta_{s}$ - pitch angle;

$\varphi_{s}-$ roll angle;

$$
\left[\begin{array}{c}
X_{S} \\
Y_{s} \\
Z_{s}
\end{array}\right]=N_{C s O T u}\left[\begin{array}{l}
x_{T u} \\
y_{T u} \\
z_{T u}
\end{array}\right]
$$

(local system $\left\{C_{s}\right\}$ vs. local system $\left\{O_{T u}\right\}$, as defined above);

$$
N_{\mathrm{CsOTu}}=\left[\begin{array}{ccc}
\cos \delta_{u} & -\sin \delta_{u} & 0 \\
\sin \delta_{u} & \cos \delta_{u} & 0 \\
0 & 0 & 1
\end{array}\right]
$$

where:

$\delta_{u}$-steering angle of the front left and front right wheel of the motor vehicle $(u=[1,2])$.

The steering angles of individual wheels are in conformity with the Ackermann model and are determined by the steering wheel angle $\delta_{H}$. The values of this angle are calculated in the control system (Figure 3). 
For the non-steerable wheels, the coordinate systems $\left\{O_{T 3}\right\}$ and $\left\{O_{T 4}\right\}$ are parallel to the $\left\{C_{A}\right\}$ system and the $\left\{O_{T 5}\right\}$ and $\left\{O_{T 6}\right\}$ systems are parallel to the $\left\{C_{B}\right\}$ system. The transforms describing the interdependence between these systems are unit matrices (e.g., Equation (7) for $\delta_{u}=0$ ).

The physical model of the motorcar consists of a vehicle body and 4 road wheels; for the trailer, the physical model consists of a trailer body and 2 wheels. The models of dynamics of the car and the trailer, if treated separately, have 10 and 8 degrees of freedom, respectively. When the motorcar and the trailer are coupled together by means of a ball joint $O_{A B}$ (Figure 6), constraints are imposed on the trailer's motion and the number of the degrees of freedom of the CT unit is thus reduced to 15.

The set of the generalized coordinates, which completely define the car and trailer's positions, may be written as follows:

$$
\begin{gathered}
q_{A}=\left[x_{A} y_{A} z_{A} \psi_{A} \theta_{A} \varphi_{A} \omega_{1} \omega_{2} \omega_{3} \omega_{4}\right]^{T} \\
q_{B}=\left[\psi_{B} \theta_{B} \varphi_{B} \omega_{5} \omega_{6}\right]^{T}
\end{gathered}
$$

The CT unit's motion can be described by vectorial equations $[30,31]$ :

$$
\begin{gathered}
m_{s}\left(\ddot{r}_{s}+\boldsymbol{\Omega}_{s} \times \dot{r}_{s}\right)=\sum_{i}^{n} \boldsymbol{F}_{s i} \\
\boldsymbol{T}_{s} \dot{\Omega}_{s}+\boldsymbol{\Omega}_{s} \times \boldsymbol{T}_{s} \boldsymbol{\Omega}_{s}=\sum_{j}^{k} \boldsymbol{M}_{s j}
\end{gathered}
$$

where:

$m_{s}$-vehicle mass;

$r_{s}$-vector from the origin of the global coordinate system to the center of mass $C_{s}$ in the global coordinate system $\{O\} ; \boldsymbol{r}_{s}=\left[\begin{array}{lll}x_{s} & y_{s} & z_{s}\end{array}\right]^{T}$ (cf. Figure 6); $\dot{\boldsymbol{r}}_{\boldsymbol{s}}=\boldsymbol{v}_{\boldsymbol{s}} ; \ddot{\boldsymbol{r}}_{s}=\boldsymbol{a}_{\boldsymbol{s}}$;

$\boldsymbol{F}_{s i}, \boldsymbol{M}_{s j}$ - generalized external forces and moments acting on vehicles;

$T_{s}$-tensor of inertia of vehicle $s$ relative to the vehicle center of mass in the local coordinate system $\left\{C_{s}\right\}$;

$\Omega_{s}$-vector of the yaw velocity of the body of vehicle $s$ in the local coordinate system $\left\{C_{s}\right\}$; $\Omega_{s}=\left[\begin{array}{lll}\dot{\varphi}_{s} & \dot{\theta}_{s} & \dot{\psi}_{s}\end{array}\right]^{T}$.

\subsubsection{Forces in the Vehicle-Trailer Coupling Device}

The generalized external forces $F_{s i}$ also include the coupling device force $R_{s}$. The coupling device equation, being at the same time an equation of the constraints imposed upon the trailer, has been written as follows:

$$
\begin{aligned}
& R_{A X}+R_{B X}=\Delta R_{1 z a d} \\
& R_{A Y}+R_{B Y}=\Delta R_{2 z a d} \\
& R_{A Z}+R_{B Z}=\Delta R_{3 z a d}
\end{aligned}
$$

where:

$R_{A X}, R_{A Y}, R_{A Z}, R_{B X}, R_{B Y}, R_{B Z}$ - components of the coupling device force for motorcar $A$ and trailer $B$, as appropriate, calculated in every step of the integration of model equations and expressed in the global coordinate system $\{O\}$;

$\Delta R_{1 z a d}, \Delta R_{2 z a d}, \Delta R_{3 z a d}$-acceptable values of the differences between components of the coupling device force.

\subsubsection{Model of the Tire-Road Interaction}

The tire-road interaction has been described with the use of the non-linear TMeasy model [33-36]. This model makes it possible to determine the external forces $F_{x T}$ and $F_{y T}$, 
generated in the tire-road contact area and acting from the road via the suspension system onto the vehicle. These forces are functions of the normal tyre-road contact force $F_{z T}(t)$ and of the longitudinal tyre slip ratio $s_{x T}$ and lateral tyre slip ratio $s_{y T}$; for individual wheels, they are calculated from equations:

$$
\begin{aligned}
& F_{x T}\left(s_{x T}, t\right)=\mu \mu_{x}\left(s_{x T}\right) F_{z T}(t) \\
& F_{y T}\left(s_{y T}, t\right)=\mu \mu_{y}\left(s_{y T}\right) F_{z T}(t)
\end{aligned}
$$

where:

$\mu$-local tire-road adhesion coefficient;

$\mu_{x}\left(s_{x T}\right), \mu_{y}\left(s_{y T}\right)$ - unit longitudinal and lateral forces as characteristics describing the properties of a specific tire model as functions of tire slip ratio;

$F_{z T}(t)$-current value of the normal tire-road contact force for each wheel.

Figure 7 shows, inter alia, the tire velocity vectors, which are necessary for determining the tire slip ratio. The position of the center of the tire-road contact area (point $O_{T}$ ) has been defined using the local coordinate systems attached to vehicle bodies $\left\{C_{s}\right\}$ and to vehicle wheels $\left\{O_{T} x_{T} y_{T} z_{T}\right\}$, shown in Figure 6.
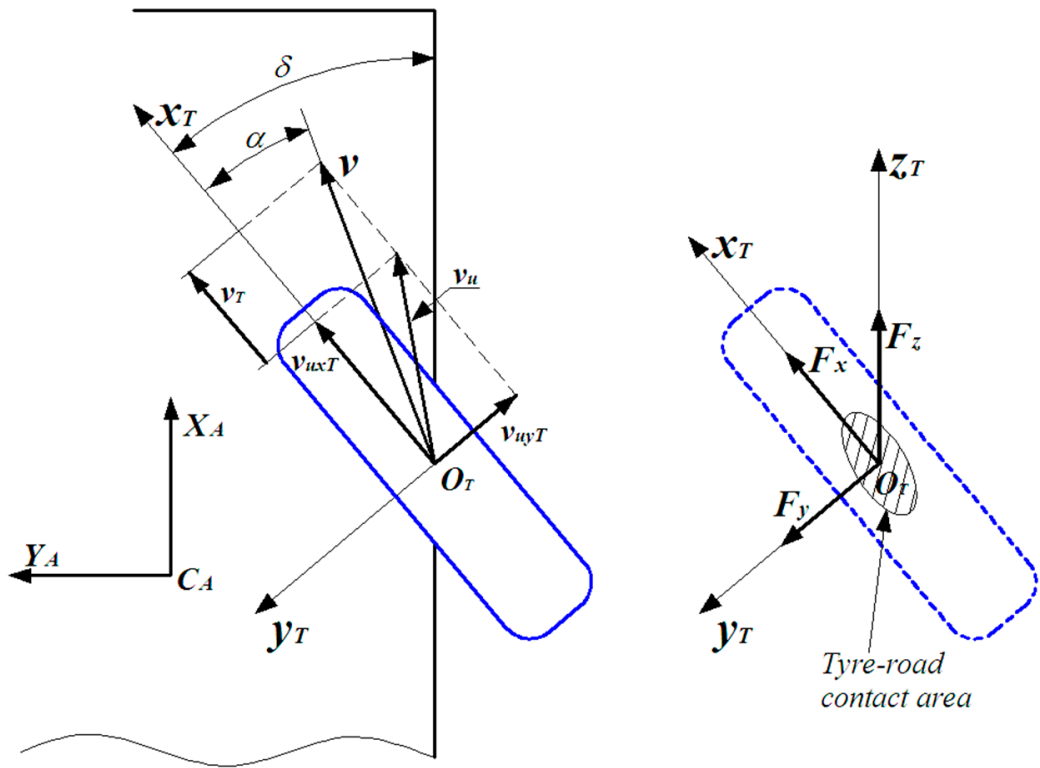

Figure 7. Kinematics and dynamics of the steerable wheel.

Based on Figure 7, the longitudinal tire slip ratio $s_{x T}$ and lateral tyre slip ratio $s_{y T}$ have been determined for the $u$ th wheel:

$$
\begin{aligned}
& s_{x T}=\frac{v_{u x T}}{\left(v_{T}+v_{u x T}\right)} \\
& s_{y T}=\frac{v_{u y T}}{\left(v_{T}+v_{u x T}\right)}
\end{aligned}
$$

where:

$v_{u}-u$ th wheel slip velocity, resulting from longitudinal and lateral slip velocities, i.e., $v_{u x T}$ and $v_{u y T}$, respectively;

$v_{T}+v_{u x T}$-longitudinal component of the wheel center velocity vector;

$v_{T}$ - circumferential velocity of the tire, resulting from the rotational wheel motion.

The tire sideslip angle has been determined from the equation:

$$
\alpha=-\arctan \frac{v_{u y T}}{\left(v_{T}+v_{u x T}\right)}
$$


The values of the tire slip ratios according to (15) and (16) are necessary to calculate the forces $F_{x T}$ and $F_{y T}$ tangential to the road surface. The elastodynamic tire characteristics have a significant impact on the CT unit's behavior in the road situation under consideration (high traveling speed with high values of longitudinal slip ratio and sideslip angle of vehicle tires).

The tire model parameter values taken for this study have been based on the results of the experimental testing of tires 185R14C and 235/60R16 [37-39].

Figure 8 shows an example comparison of tangential force curves $F_{x}\left(s_{x}\right)$ and $F_{y}\left(s_{y}\right)$ for tests carried out on road surfaces with adhesion coefficients of $\mu_{1}=0.8$ (dry asphalt concrete) and $\mu_{2}=0.8$ (wet road). The $F_{y}(\alpha)$ curve has been plotted for only one road surface type. The curves presented show that the maximum values of the tangential reactions at the tire-road contact area occur at a slip ratio of about 0.15 and a tire sideslip angle of about $8 \mathrm{deg}$. Further growth in the slip ratio causes a reduction in the tangential reactions and, in consequence, increasing deviation of the vehicle's motion from the trajectory planned.
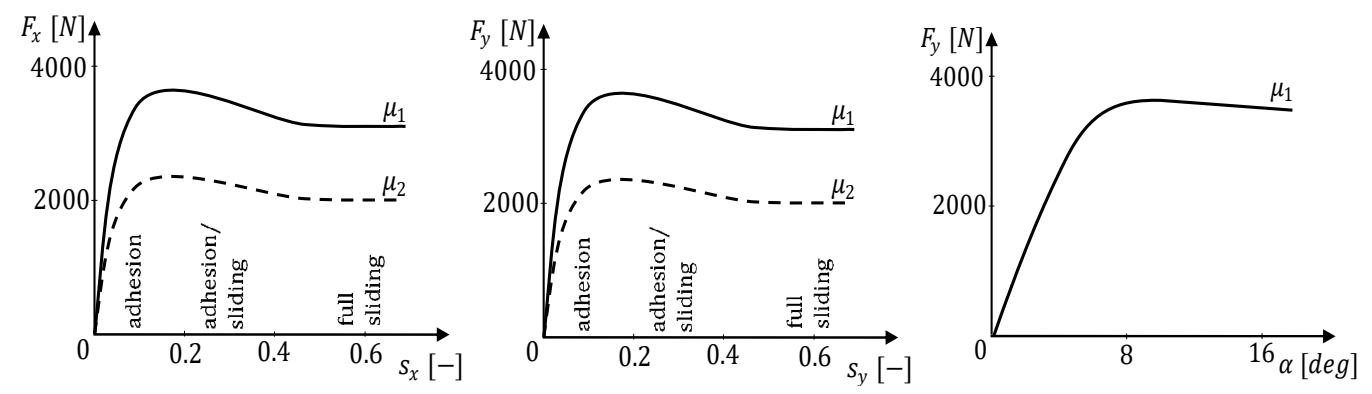

Figure 8. Non-linear characteristics of the dependence of tangential reactions on tire slip ratio and sideslip angle.

\section{Validation of the Model of a CT Unit}

The model validation was preceded by a parametrization process based on the results of measurements of mass distribution, as well as dimensions and characteristics of the suspension system and tires, carried out on the vehicle combination under test. The vehicle combination under test can be seen in Figure 9, when it was performing a dynamic lanechange maneuver according to the ISO 3888-1 standard [40]. Results of the measurements carried out were compared with results of simulation of a double lane-change maneuver.
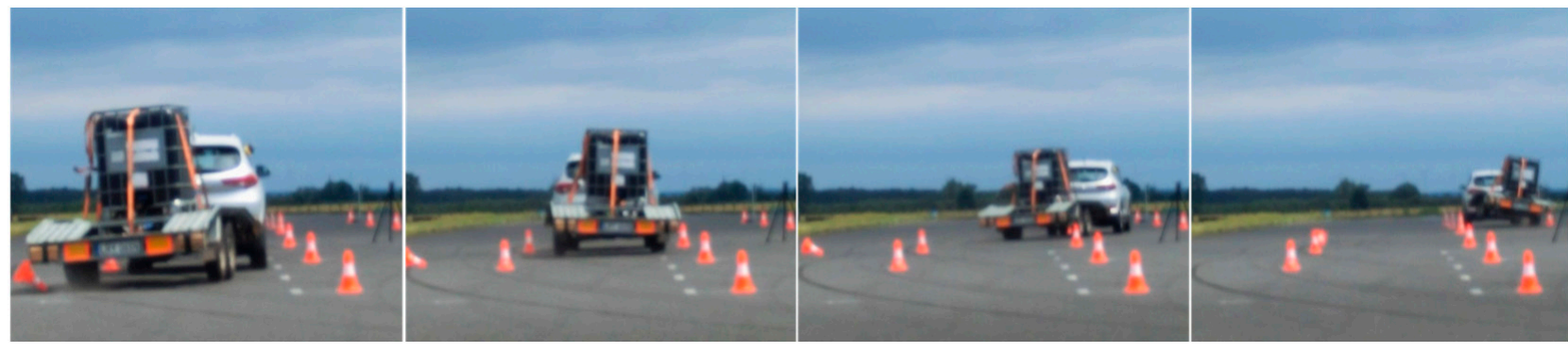

Figure 9. Experimental tests.

During the validation tests, a road infrastructure model according to the ISO 3888-1 standard and a CT unit control system model according to Figures 2, 3 and 5 were also used. The trajectory of the center of mass of the motorcar model $y_{M}(x)$ was specially selected for the steering wheel angle $\delta_{H}(x)$ obtained to be in conformity with the curve recorded during the experimental tests. The result of such a model validation procedure has been presented in Figure 10. 




Figure 10. Comparison of the steering wheel angle curves $\delta_{H}(x)$ obtained in the model tests and experimental tests carried out to validate the CT model.

Example comparisons of results of the experimental and simulation tests have been presented in Figure 11.
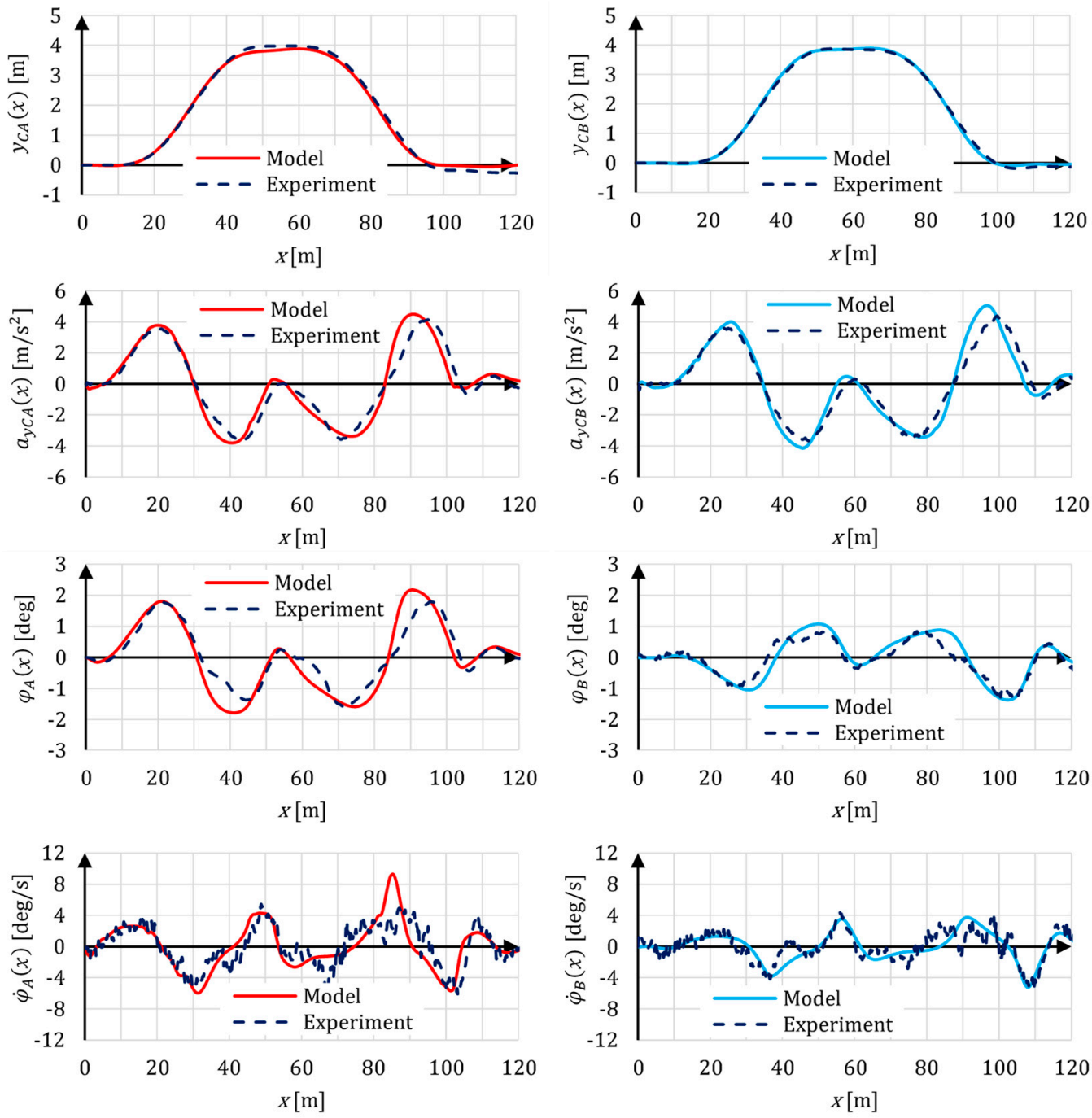

Figure 11. Cont. 

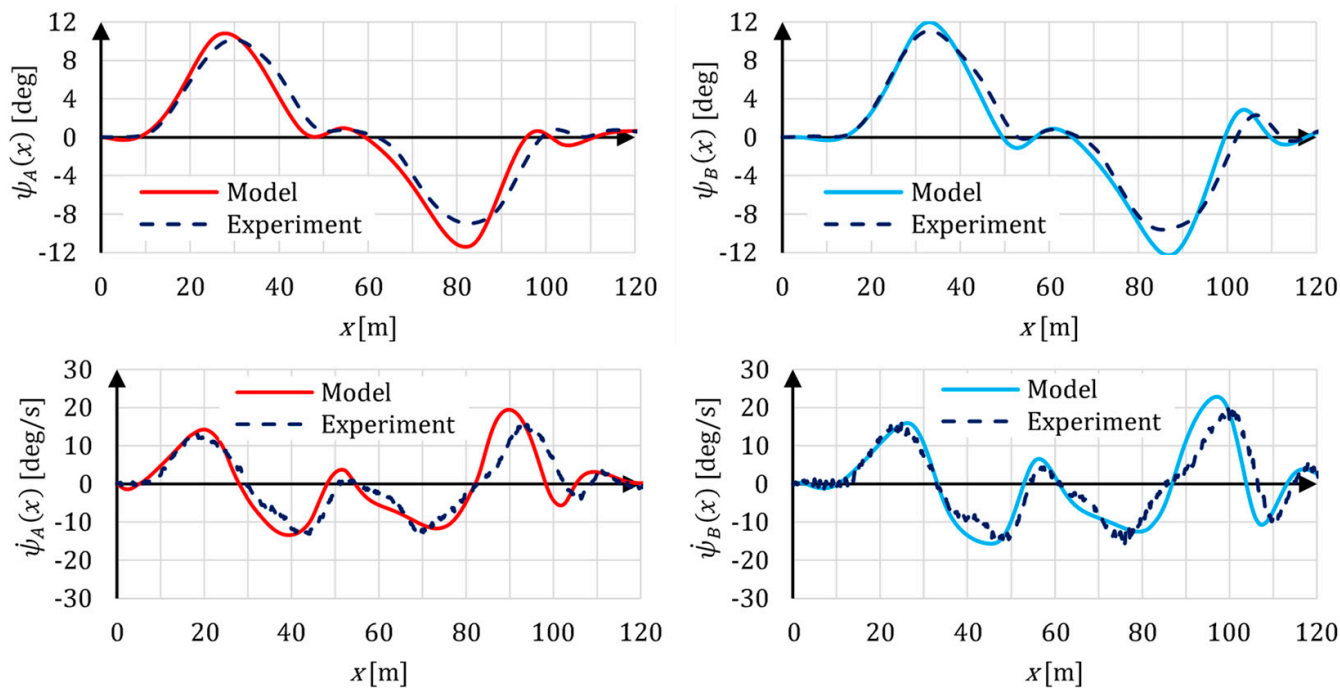

Figure 11. Comparison of results of the experimental and simulation tests of the CT unit performing a double lane-change maneuver with a speed of $v=60 \mathrm{~km} / \mathrm{h}$ (left: motorcar; right: trailer).

Figure 11 shows the validation results. For model validation purposes, the following results of the model and experimental tests have been compared with each other, separately for the motorcar $(s=A)$ and for the trailer $(s=B)$ : trajectory $y_{C s}(x)$ and lateral acceleration $a_{y C_{S}}(x)$ of the centre of vehicle mass, vehicle roll angle $\varphi_{s}(x)$ and velocity $\dot{\varphi}_{s}(x)$, and vehicle yaw angle $\psi_{s}(x)$ and velocity $\dot{\psi}_{s}(x)$. The conformity between the extreme and mean characteristic values at various stages of the maneuver performed was analyzed. The validation process, based on the results of parametrization of the CT unit and control system models, resulted in the obtaining of good consistency between the kinematics of the model and the actual motion of the real object (i.e., the motorcar and the trailer). The results of this highly multi-aspect assessment may be considered as confirming good agreement between the profiles of individual physical quantities, which means good agreement between the characteristics of the object and its model.

\section{Calculation of Trajectory $y_{M}(x)$}

\subsection{Data Necessary to Plan the Obstacle-Avoiding Trajectory}

At first, the control system calculates trajectory $y_{M}(x)$ (Figures 2 and 3). The calculations are based on the information received from the environment perception system that a critical situation has arisen. The process of analyzing the critical situation begins at the instant when the perception system identifies the appearance of an obstacle $\left(y_{0}>0\right)$ on the lane used by the vehicle at a distance of $x_{0}$ ahead (Figure 1). If $x_{0}<S_{Z}$ then the obstacle avoidance procedure is started. $S_{Z}$ is the length of the stopping distance of the CT unit in the current local road conditions. The trajectory $y_{M}(x)$ necessary for safe obstacle avoidance is calculated with taking into account the following:

- The trajectory $y_{M}(x)$ planned is to be a continuation of the preceding path of the vehicle and to include smooth transition from straight-line motion to curvilinear motion (Figure 1), with the obstacle position being taken into account.

- Trajectory $y_{M}(x)$ is designed in a two-dimensional space, based on the information obtained from the system of perception of the situation in front of the vehicle.

- $\quad$ The positions of point $K$ and target point $P$ (see (1)) are predicted based on the information provided by the environment perception system and on the method pre-programmed in the control system for critical situations.

- An assumption is made that the curvature of the trajectory section where $0.5 x_{0}<x<x_{0}$ should be opposite to that of the section where $0<x<0.5 x_{0}$ and its absolute value should not exceed that of the latter. 
When trajectory $y_{M}(x)$ is calculated, the following limitations posed by the design features of the CT unit must be taken into account:

$$
\begin{gathered}
\delta \leq \delta_{M A X}=30 \ldots 35 \mathrm{deg}-\text { confinement of the steering angle; } \\
R_{A \mathrm{MIN}} \geq \frac{L}{\operatorname{tg} \delta_{M A X}} R_{B M I N} \geq \sqrt{R_{A M I N}^{2}+l_{h}^{2}-l_{h p}^{2}}
\end{gathered}
$$

where:

$R_{A M I N}, R_{B \text { MIN }}$-minimum radii of curvature of car and trailer's trajectories, respectively; $L$-motorcar's wheelbase;

$l_{h}$ and $l_{h p}$-distances from the coupling device centerline to the rear axle of the towing vehicle and to the trailer axle, respectively.

\subsection{Methods Considered and Their Calculational Models}

In result of an analysis of the methods of planning a safe vehicle trajectory $[1,9,20]$, the functions based on a cosine curve, circular arcs, and parabola segments were selected for further consideration. Thus, the following functions, going through point $P\left(x_{0} ; y_{P}\right)$, have been used for designing the trajectory in the global coordinate system based on lane edge $R_{\text {min }}$ (Figure 1):

1. Cosine curve (dark blue in Figure 12):

$$
y_{M}(x)=0.5\left(y_{P}-0.5 d\right)\left(1-\cos \left(\frac{x}{x_{0}} 180^{\circ}\right)\right)+0.5 d \text { for } x \in\left\langle 0 ; x_{0}\right)
$$

2. Circular arcs tangent to each other at point $M_{1}\left(0.5 x_{0} ; 0.5\left(y_{P}-0.5 d\right)+0.5 d\right)$, with identical radius $R_{0}$ (red in Figure 12):

$$
\begin{gathered}
y_{M}(x)=R_{0}-\sqrt{R_{0}^{2}-x^{2}}+0.5 d \text { for } x \in\left\langle 0 ; 0.5 x_{0}\right) \\
y_{M}(x)=\sqrt{R_{0}^{2}-\left(x-x_{0}\right)^{2}}+y_{P}-R_{0} \text { for } x \in\left\langle 0.5 x_{0} ; x_{0}\right) \\
R_{0}=0.25 \frac{x_{0}^{2}+\left(y_{P}-0.5 d\right)^{2}}{y_{P}-0.5 d}
\end{gathered}
$$

3. Two parabolas tangent to each other at point $M_{2}\left(0.1 x_{0} ; 0.1\left(y_{P}-0.5 d\right)+0.5 d\right)$, (green in Figure 12, defined by equations):

$$
\begin{gathered}
y_{M}(x)=a_{1} x^{2}+0.5 d \text { for } x \in\left\langle 0 ; 0.1 x_{0}\right) \\
a_{1}=\frac{0.1\left(y_{P}-0.5 d\right)}{\left(0.1 x_{0}\right)^{2}} \\
y_{M}(x)=a_{2}\left(x-x_{0}\right)^{2}+y_{P} \text { for } x \in\left\langle 0.1 x_{0} ; x_{0}\right) \\
a_{2}=\frac{-0.9\left(y_{P}-0.5 d\right)}{\left(0.1 x_{0}-x_{0}\right)^{2}}
\end{gathered}
$$




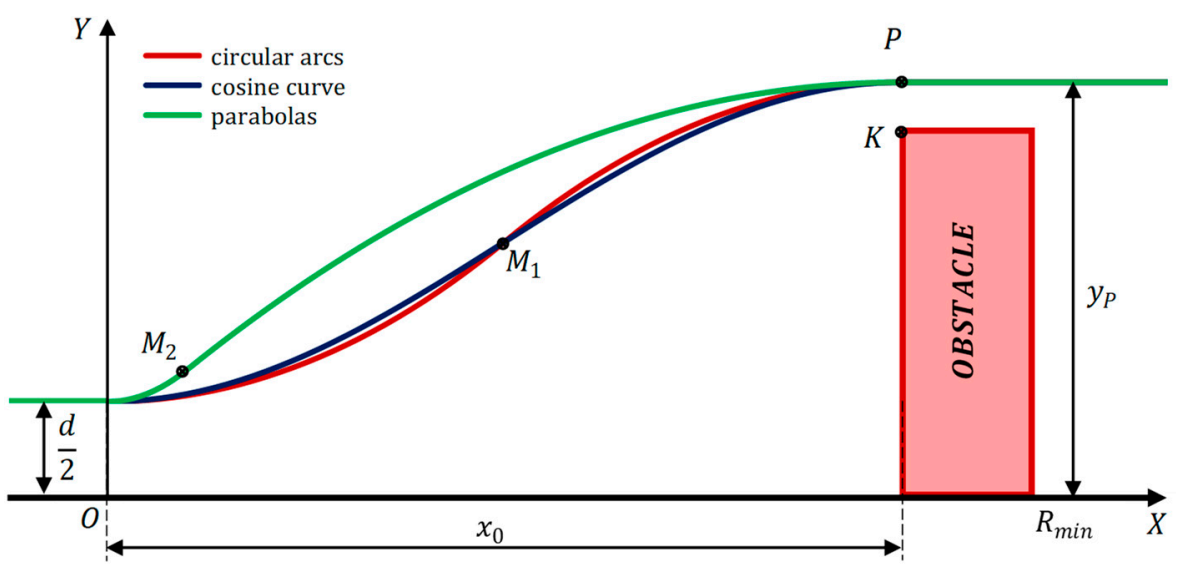

Figure 12. Shapes of trajectory $y_{M}(x)$, obtained from the three trajectory calculation methods.

\section{Test Results Concerning the Selection of a Method to Calculate the CT Unit Trajectory in a Critical Situation}

6.1. Assumptions Adopted for The Simulation Tests at the Method Selection Stage

The properties of the control system depend on many factors. These factors were divided into three groups: constant, temporary, and variable ones. The group of temporary factors included the trajectory planning algorithm and the $L_{a}$ value. As a variable factor, the clearance margin $\left(y_{W}\right)$ value, applied as a parameter to the control system, is considered. Tests were prepared to select the said factors for the critical situation under consideration. The following main assumptions were adopted for the simulation tests:

- The CT unit consisted of a motorcar with a mass of $1800 \mathrm{~kg}$ and a centre-axle trailer with a mass of $1800 \mathrm{~kg}$ as well.

- Before the critical situation arose, the CT unit moved rectilinearly with a constant speed $(v=$ const.) in the middle of the right lane of a carriageway.

- The level and flat road had two lanes with a width of $d=4 \mathrm{~m}$ each and a shoulder $1 \mathrm{~m}$ wide.

- $\quad$ The width of the CT unit was $b=2 \mathrm{~m}$.

When the model parameter values were selected, the maximum possible trailer weight was assumed. Such a choice has a favorable impact on transport efficiency but adversely affects the stability of motion of a CT unit along a curvilinear path [14].

At this stage, the tests were carried out for the following solution alternatives examined:

- $\quad$ three trajectory planning methods (computationally described by Equations (20)-(22));

- four values of the CT unit's speed $(v=40 \mathrm{~km} / \mathrm{h}, 60 \mathrm{~km} / \mathrm{h}, 70 \mathrm{~km} / \mathrm{h}$, and $80 \mathrm{~km} / \mathrm{h})$;

- five values of the anticipation radius $\left(L_{a}=4 \mathrm{~m}, 6 \mathrm{~m}, 8 \mathrm{~m}, 10 \mathrm{~m}\right.$, and $\left.12 \mathrm{~m}\right)$;

- $\quad$ seven clearance margin values $\left(y_{W}=0 \mathrm{~m}, 0.25 \mathrm{~m}, 0.5 \mathrm{~m}, 0.75 \mathrm{~m}, 1.0 \mathrm{~m}, 1.5 \mathrm{~m}\right.$, and $2.0 \mathrm{~m}$ );

- $\quad$ two states of the asphalt concrete road surface (dry and wet).

While the simulation tests covered so many solution alternatives, only one critical situation was addressed, where another motor vehicle suddenly appeared on a road intersection with poor visibility and blocked the whole width of the lane used by the CT unit (Figure 1).

\subsection{Example of Calculation Results}

Simulation tests were carried out for 840 trajectory planning alternatives, as described above. Fragments of the calculation results have been presented in Figures 13-15 and in Table 1; a complete set of the results will be used in the procedure of selecting a method to calculate the CT unit trajectory and the $L_{a}$ value. Figure 13 shows the courses of the trajectories $y_{M}(x)$ and $y_{T}(x)$ determined for different $L_{a}$ values (according to (2)) and for three vehicle trajectory calculation methods. Trajectory $y_{M}(x)$ has been plotted with a 
dotted line. Figure 13A,C,E (on the left) show examples of trajectories of the CT unit moving with a speed of $v=60 \mathrm{~km} / \mathrm{h}$; on the right (Figure 13B,D,F), there are model responses obtained for each of the trajectory planning methods and for three vehicle speed values. The obstacle avoidance process obtained for three trajectory calculation alternatives and for vehicle speeds $v=60 \mathrm{~km} / \mathrm{h}, 70 \mathrm{~km} / \mathrm{h}$, and $80 \mathrm{~km} / \mathrm{h}$ has been presented in Figure 14 . Figure 15 shows a comparison of animations of the CT unit's motion on dry and wet road surfaces.
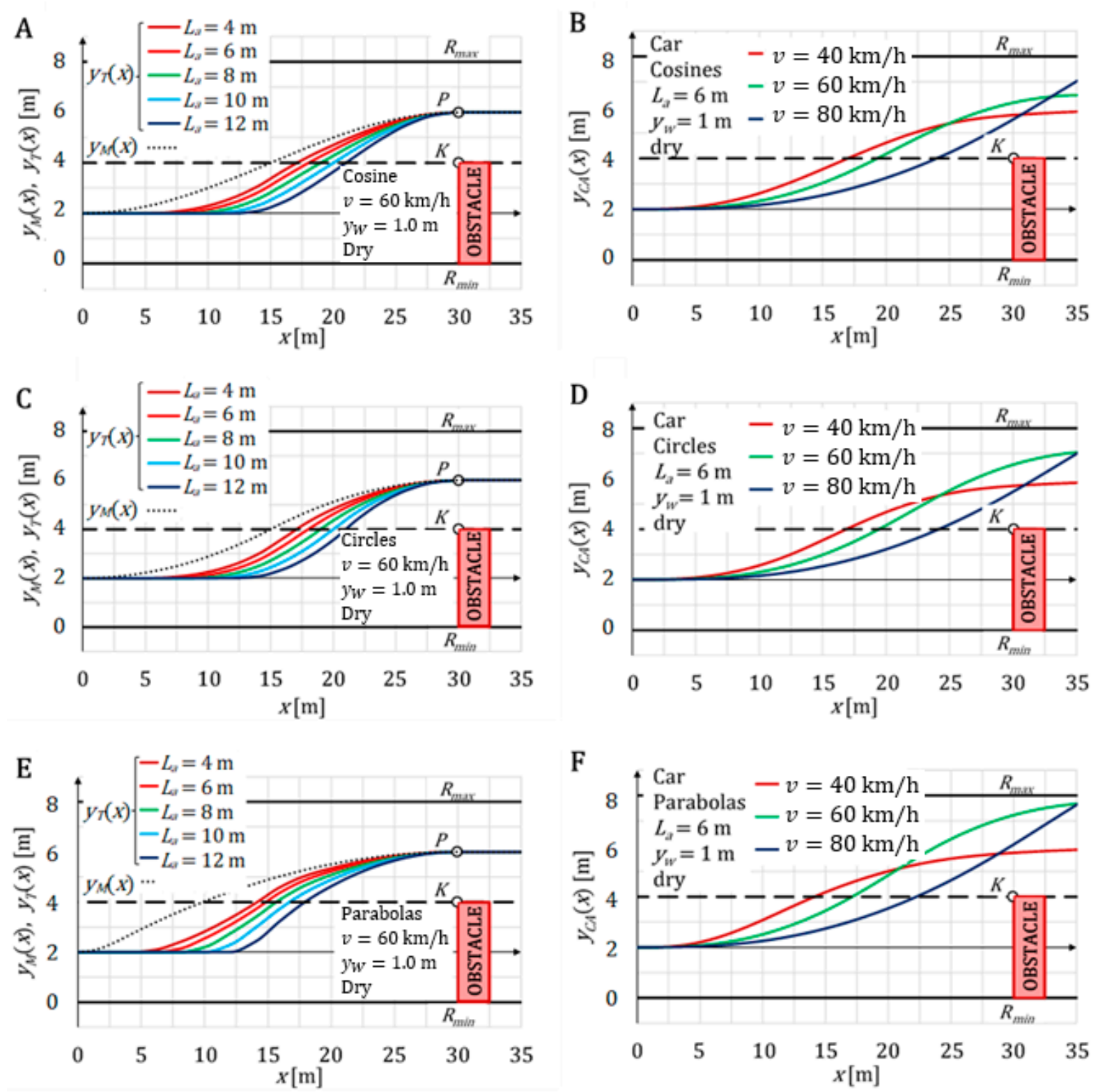

Figure 13. Comparison of trajectories $y_{M}(x)$ and $y_{T}(x)$ for different trajectory calculation methods (left) and of car paths $y_{C A}(x)$ obtained (right) for dry road surface; $(\mathbf{A}, \mathbf{B})$ - method with a cosine curve; $(\mathbf{C}, \mathbf{D})$ - method with circular arcs; $(\mathbf{E}, \mathbf{F})$ - method with parabolas. 


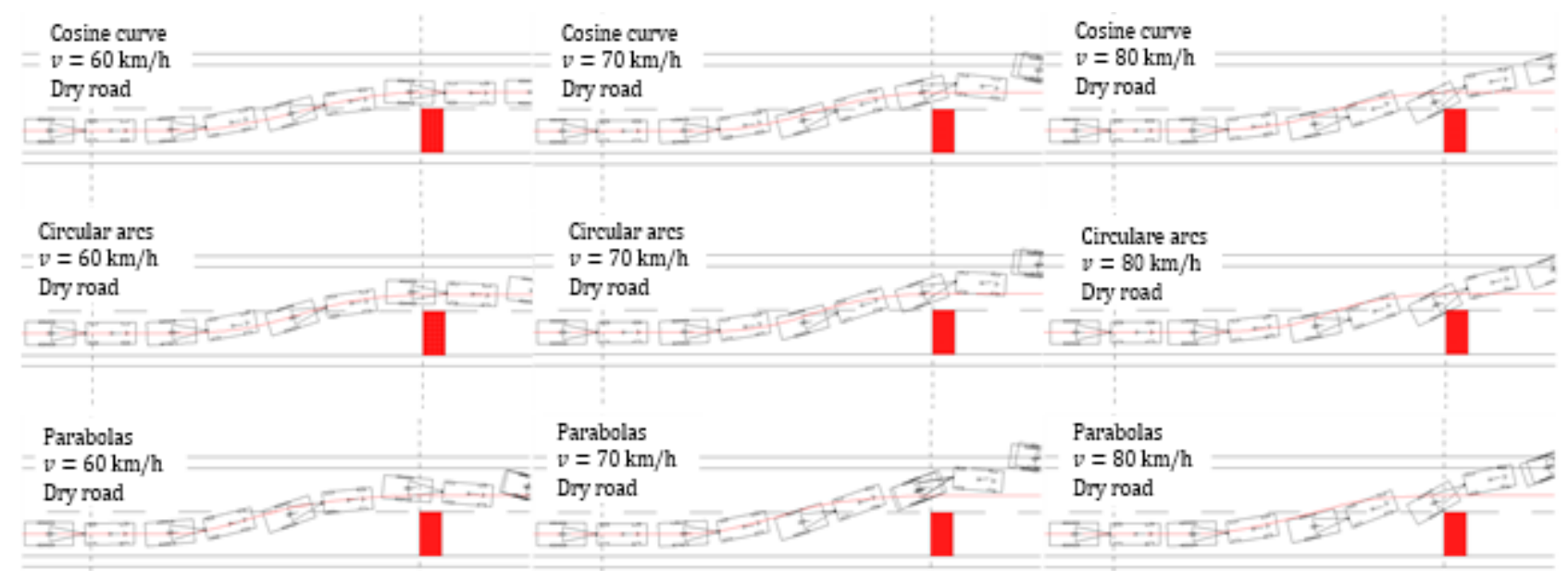

Figure 14. Comparison of animations of the CT unit's motion for $v=60 \mathrm{~km} / \mathrm{h}, 70 \mathrm{~km} / \mathrm{h}$ and $80 \mathrm{~km} / \mathrm{h}$ and for three $y_{M}(x)$ determination methods; dry road surface.

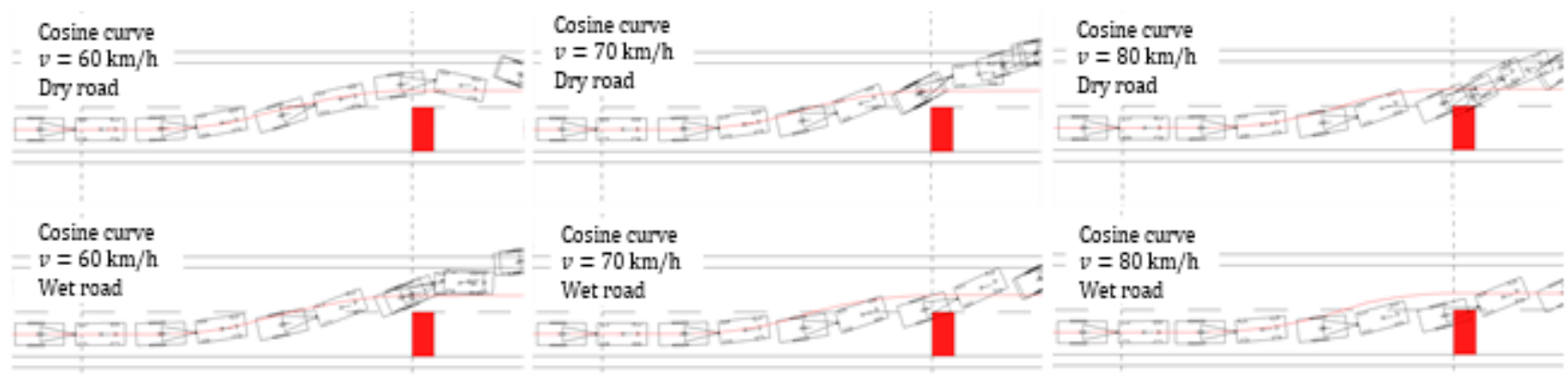

Figure 15. Comparison of animations of the CT unit's motion on dry and wet road surface for $v=60 \mathrm{~km} / \mathrm{h}, 70 \mathrm{~km} / \mathrm{h}$ and $80 \mathrm{~km} / \mathrm{h}$; trajectory calculation method with a cosine curve.

This brief summary of research results shows the impact of the $y_{M}(x)$ calculation method on the obstacle avoidance process. The example presented in Figure 13 indicates the favorable course of the process when the methods with a cosine curve or circular arcs are used to calculate $y_{M}(x)$. In Figure 14, we can see that the cosine method produced an advantageous effect for $v=70 \mathrm{~km} / \mathrm{h}$, but for $v=80 \mathrm{~km} / \mathrm{h}$, the trajectory calculated by the method with parabolas is better. For the wet road (Figure 15), good results were obtained for $v=60 \mathrm{~km} / \mathrm{h}$ and the cosine method. The selection of $L_{a}$, in turn, has an impact on the trajectory curvature in each of the methods under consideration. For rising vehicle speed values, increasing the impact of the trajectory planning methods on the course of the obstacle avoidance process can be observed in the analysis.

This means that to select the optimum method of planning the trajectory $y_{M}(x)$ and value $L_{a}$, a lot of obstacle avoidance alternatives and curves representing changes in various physical quantities, obtained as simulation results, must be taken into consideration, because each of them helps to describe a different aspect of vehicles' behavior in a critical situation. 
Table 1. Fragment of a set of results of simulations of CT unit's motion during an obstacle avoidance maneuver.

\begin{tabular}{|c|c|c|c|c|c|c|c|c|c|c|c|c|c|c|c|}
\hline \multirow{2}{*}{ Vehicle $s$} & \multirow{2}{*}{$v[\mathrm{~km} / \mathrm{h}]$} & \multirow{2}{*}{$y_{W}[\mathrm{~m}]$} & \multirow{2}{*}{$\begin{array}{c}y_{P} \\
{[\mathrm{~m}]}\end{array}$} & \multirow{2}{*}{$\begin{array}{c}x\left(y_{C_{S}}=y_{P}\right) \\
{[\mathrm{m}]}\end{array}$} & \multirow{2}{*}{$\begin{array}{c}\text { Safe Avoidance of } \\
\text { the Obstacle [-] }\end{array}$} & \multirow{2}{*}{$\begin{array}{c}\text { Stay in the } \\
\text { Lane [-] }\end{array}$} & \multirow{2}{*}{$\begin{array}{c}\alpha_{E k s t r} \\
x \in\left(\mathbf{0} ; 0.5 x_{0}>\right. \\
{[\text { deg] }}\end{array}$} & \multirow{2}{*}{$\begin{array}{c}\alpha_{E k s t r} \\
x \in\left(0.5 x_{0} ; \mathbf{x}_{0}>\right. \\
{[\text { deg] }}\end{array}$} & \multirow{2}{*}{$\begin{array}{c}\alpha_{\text {Ekstr }} \\
x \in\left(x_{0} ; 1.33 x_{0}>\right. \\
{[\text { deg] }}\end{array}$} & \multirow{2}{*}{$\begin{array}{c}a_{y \text { Ekstr }} \\
x \in\left(0 ; 0.5 x_{0}>\right. \\
{\left[\mathrm{m} / \mathrm{s}^{2}\right]}\end{array}$} & \multirow{2}{*}{$\begin{array}{c}a_{y E k s t r} \\
x \in\left(0.5 x_{0} ; x_{0}>\right. \\
{\left[\mathrm{m} / \mathrm{s}^{2}\right]}\end{array}$} & \multirow{2}{*}{$\begin{array}{c}a_{y \in k s t r} \\
x \in\left(x_{0} ; 1.33 x_{0}>\right. \\
{\left[\mathrm{m} / \mathbf{s}^{2}\right]}\end{array}$} & \multirow{2}{*}{$\begin{array}{c}\Delta \Psi_{\text {Ekstr }} \\
x \in\left(0 ; x_{0}>\text { [deg] }\right.\end{array}$} & \multicolumn{2}{|c|}{$y_{K}[\mathrm{~m}]$} \\
\hline & & & & & & & & & & & & & & $N_{F R}$ & $N_{R R}$ \\
\hline 1 & 2 & 3 & 4 & 5 & 6 & 7 & 8 & 9 & 10 & 11 & 12 & 13 & 14 & 15 & 16 \\
\hline A & 40 & 0.0 & 5.0 & $>40$ & $\mathrm{NO}$ & YES & 1.26 & 1.17 & 0.38 & 1.99 & 2.00 & 0.68 & 0 & -0.21 & -0.23 \\
\hline A & 60 & 0.25 & 5.25 & 29.79 & YES & $\mathrm{NO}$ & 4.46 & 8.42 & 10.23 & 4.39 & 4.79 & 4.79 & 0 & 0.12 & 0.66 \\
\hline A & 70 & 1.75 & 6.75 & 25.36 & YES & $\mathrm{NO}$ & 6.52 & 12.57 & 11.96 & 5.71 & 5.77 & 4.26 & 0 & 2.40 & 1.33 \\
\hline A & 70 & 2.0 & 7.0 & 25.36 & YES & $\mathrm{NO}$ & 6.57 & 12.66 & 12.16 & 5.71 & 5.76 & 4.26 & 0 & 2.43 & 1.34 \\
\hline B & 60 & 0.0 & 5.0 & 26.61 & YES & YES & 3.96 & 6.46 & 12.94 & 4.82 & 6.02 & 6.55 & 13.28 & 0.46 & 0.92 \\
\hline B & 60 & 0.25 & 5.25 & 26.60 & YES & YES & 4.05 & 6.52 & 15.12 & 4.92 & 6.02 & 6.69 & 14.42 & 0.62 & 1.09 \\
\hline B & 70 & 1.75 & 6.75 & 27.74 & YES & $\mathrm{NO}$ & 3.77 & 14.57 & 19.07 & 5.01 & 6.85 & 6.85 & 12.39 & 1.30 & 0.01 \\
\hline B & 70 & 2.0 & 7.0 & 27.74 & YES & NO & 3.78 & 14.48 & 19.41 & 5.02 & 6.76 & 6.85 & 12.44 & 1.32 & 0.02 \\
\hline
\end{tabular}

In the table, the vehicle corners have been given symbols according to the $N_{i s}$ system, where $i=\{F R, R R\}$ (Front Right, Rear Right) and $s=\{A, B\}$ (car and trailer, respectively). 


\subsection{Procedure of Analysing the Calculation Results}

When the best trajectory planning method and the desirable $L_{a}$ value were selected, individual simulations were treated as successive alternatives of solving the obstacle avoidance problem. The selection was based on an analysis of a set of simulation results, which included numerical values, curves recorded, and logical values.

A procedure was established, which was taken in apart from the AHP (analytic hierarchy process) method [41,42]. In that method, logical values may be used apart from numerical ones, which was of considerable importance in the assessment process. The following steps were adopted in the procedure:

1. Selection of a decision goal (referred to as "goal") as the primary criterion of assessment of the solutions available.

2. Hierarchical arranging of the criteria of analysis, which would be considered as partial goals or sub-criteria.

3. Determining of weights for individual sub-criteria.

4. Calculating of partial assessment results for individual physical quantities in the set of results of successive simulation alternatives (solutions) adopted in examining the obstacle avoidance process. The partial assessment results would be based on the product of the weights referred to in item 3 of this list and the degree of satisfying a specific criterion by the solution alternative under analysis.

5. The final assessment result and selection of the values of the target solution would be determined by aggregation of the partial assessment results.

The results of experimental and simulation tests [43] of similar processes have made it possible to formulate the following criteria of recognizing the performance of the obstacle avoidance maneuver (i.e., the criteria and sub-criteria) as correct:

- Successful avoidance of a collision with the obstacle and keeping of the CT unit within the road lanes as planned.

- Smooth growth in the lateral displacements $y_{C A}(x)$ and $y_{C B}(x)$ until the obstacle is passed by.

- Short length of the distance travelled where the "adjustment" of the vehicle position (measured by the yaw angle $\psi_{s}(x)$ ) took place and limited value of the extreme vehicle trajectory overshoot, i.e., preventing of the vehicle from leaving the lane planned.

- The lowest possible extreme values of the steering wheel angle $\delta_{H E k s t r}$, tyre sideslip angles of vehicle's rear axle and trailer's axle ( $\alpha_{A E k s t r}$ and $\alpha_{B E k s t r}$, respectively), lateral acceleration $\left(a_{y C A E k s t r}\right.$ and $\left.a_{y C B E k s t r}\right)$, and trailer drawbar turning angle $\Delta \psi$, informing that the CT unit's motion was kept stable.

The above was taken into account when the results obtained for individual solutions (i.e., the simulation results for individual alternatives) were assessed. In consequence, the following has been decided:

A Goal: safe avoidance of the obstacle.

B Criteria as partial goals:

(a) safe vehicle path, i.e., $\mathrm{CT}$ unit's motion between lines $R_{\min }$ and $R_{\max }$ (Figure 1) or $y_{C A}(x), y_{C B}(x) \in\{0.5 b ; 2 d-0.5 b\}$;

(b) vehicle's motion stability maintained, i.e., $a_{y}<a_{y M A X}$ and $\Delta \psi<\Delta \psi_{M A X}$.

C Sub-criteria:

(a) direct:

- clearance between the car side and the obstacle when the latter is being passed by $\left(y_{K A}\right)$;

- clearance between the trailer side and the obstacle $\left(y_{K B}\right)$;

(b) indirect:

- car yaw angle relative to the preset vehicle trajectory $(\Delta \beta)$;

- departure of the actual car trajectory from the planned one $\left(\left|y_{M}-y_{C A}\right|\right)$; 
- departure of the actual trailer trajectory from the planned one $\left(\left|y_{M}-y_{C B}\right|\right)$;

- stable growth in the lateral displacement $\left(y_{C A}(x)\right)$.

D Alternatives:

(a) length of the imaginary anticipation radius $\left(L_{a}\right)$ from $4 \mathrm{~m}$ to $12 \mathrm{~m}$;

(b) methods of calculation of the trajectory planned: with a cosine curve, circular arcs, and parabolas;

(c) vehicle speed $(v)$ from $40 \mathrm{~km} / \mathrm{h}$ to $80 \mathrm{~km} / \mathrm{h}$ on dry and wet road surface.

E Criterion (limit) values:

(a) Sub-criteria (Ca)

- $2.0 \mathrm{~m}>y_{K A}>0 \mathrm{~m}$;

- $2.0 \mathrm{~m}>y_{K B}>0 \mathrm{~m}$;

(b) Sub-criteria $(\mathrm{Cb})$

- $|\alpha|<16 \mathrm{deg} ;|\Delta \beta|<90 \mathrm{deg} ;$

- $\left|y_{M}-y_{C A}\right|<2 \mathrm{~m}$;

- $\left|y_{M}-y_{C B}\right|<2 \mathrm{~m}$;

- $x\left(y_{C A}=3 \mathrm{~m}\right)<25 \mathrm{~m}$.

The most desirable values of the parameters taken as the sub-criteria may be described as follows:

- $\quad$ for $(\mathrm{Ca})$, the highest weights are to be assigned to the values exceeding $0.5 \mathrm{~m}$;

- $\quad$ for $(\mathrm{Cb})$, the lower the values, the higher weights should be assigned.

\subsection{Results of Applying the Procedure That Has Been Established}

Figure 16 shows example time histories describing the physical quantities that are taken into account in the procedure presented above, i.e., the paths travelled by vehicle mass centers $y_{C A}(t)$ and $y_{C B}(t)$, tire sideslip angles $\alpha_{A}(t)$ and $\alpha_{B}(t)$, lateral accelerations $a_{y C A}(t)$ and $a_{y C B}(t)$, and trailer drawbar turning angle $\Delta \psi(t)$. To facilitate the interpretation of the graphs, curves representing the trajectory planning function $y_{M}(t)$ and the steering wheel angle $\delta_{H}(t)$ have also been plotted.
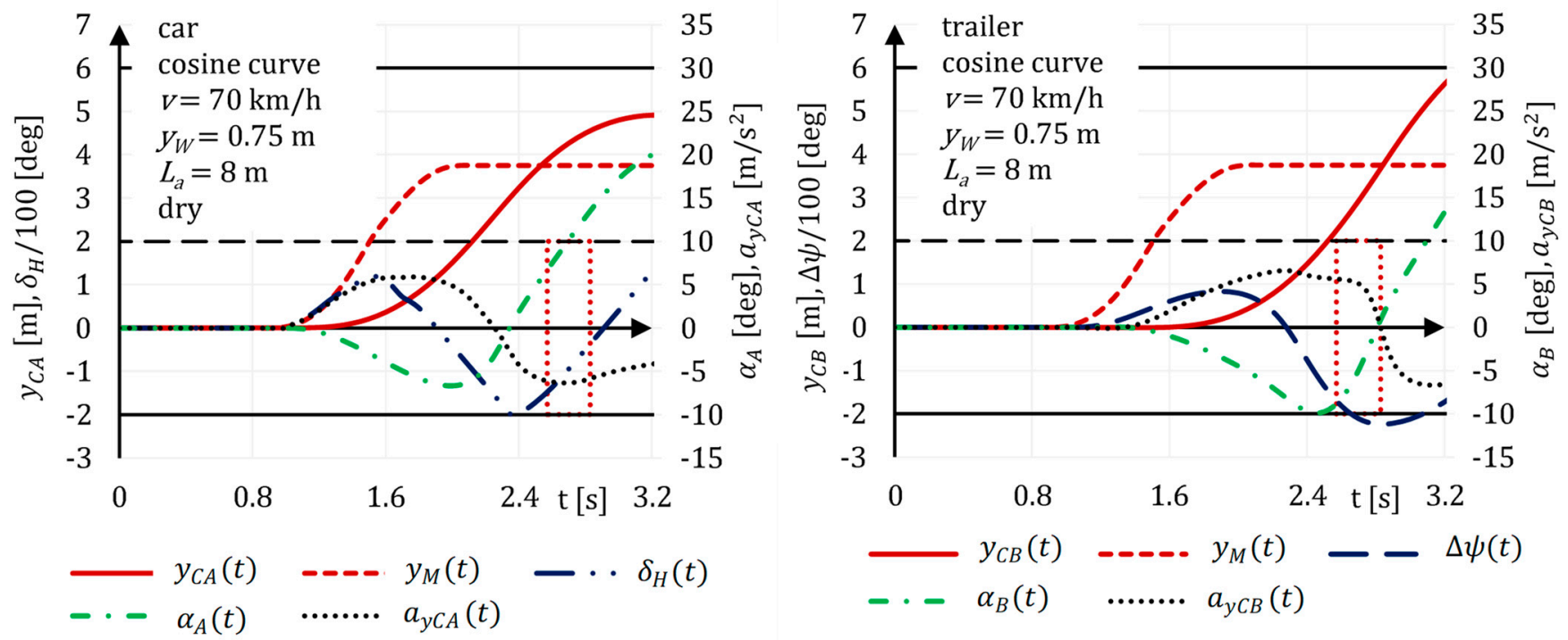

Figure 16. Curves analyzed in the procedure presented above (example obtained for the alternative with $v=70 \mathrm{~km} / \mathrm{h}$, dry road surface, and cosine method used to plan the trajectory).

To facilitate the inference, pursuant to the procedure presented, the simulation results have been brought together with respect to two points of view: 
- as a set of characteristic or extreme values of the curves analyzed that represent the car and trailer behaviors (an example is shown in Table 1);

- as a synthetic presentation of the impact of $L_{a}$ on characteristic values of some of the quantities under analysis (an example has been given in Figure 17).

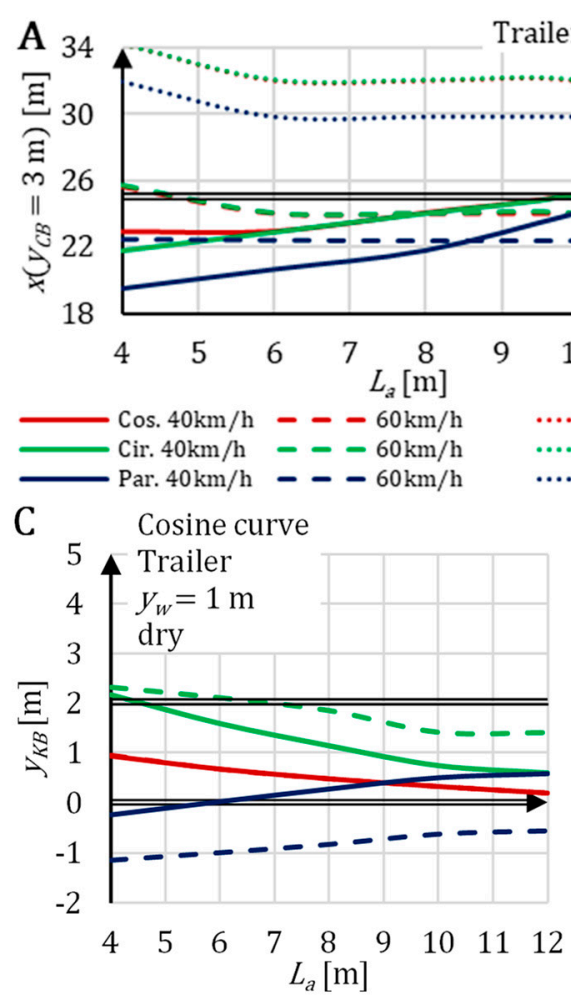

Trailer; $y_{w}=1 \mathrm{~m}$; dry $\mathbf{B}$
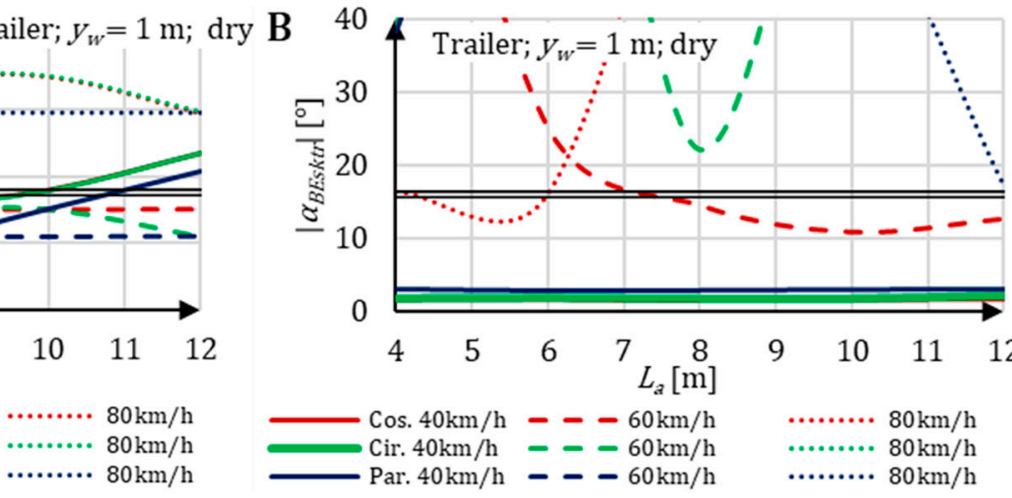

D Circural $\operatorname{arcs} 40 \mathrm{~km} / \mathrm{h} \longrightarrow \mathrm{FRB}--\mathrm{RRB} \mathrm{E}$
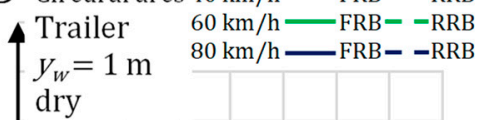

$80 \mathrm{~km} / \mathrm{h}-\mathrm{FRB}--\mathrm{RRB}$

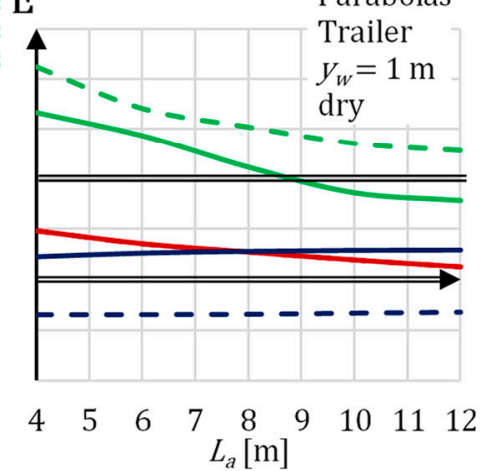

Figure 17. Summarized results of simulations of trailer's motion in a CT unit during an obstacle avoidance maneuver for three trajectory planning methods (explanation in the text above). Vehicle speed values: $v=40 \mathrm{~km} / \mathrm{h}, 60 \mathrm{~km} / \mathrm{h}$, and $80 \mathrm{~km} / \mathrm{h} ; L_{a}$ values within a range of 4-12 m; road surface: dry.

Table 1 shows a fragment of a set of results obtained for five obstacle avoidance alternatives. Such summaries of values of the physical and logic quantities determined during individual simulations were used in the procedure described above.

Figure 17 presents an example of the impact of $L_{a}$ on the results of simulation of the trailer (i.e., vehicle B) motion. In the graphs, the area of acceptable simulation results (according to the sub-criteria adopted) has been marked by double fine lines indicating the upper limit of the said area. A few curves have been plotted in the graphs that represent the functions taken into account in the procedure under consideration. In particular:

- $\quad$ Figure 17A shows the $x\left(y_{C B}=3 \mathrm{~m}\right)=f\left(L_{a}\right)$ curves, representing the distance travelled by the trailer for its lateral displacement $y_{C B}(x)$ to reach a value of $3 \mathrm{~m}$. In the graph, there is a double fine line showing the distance of $x=25 \mathrm{~m}$. The alternatives for which the $x\left(y_{C B}=3 \mathrm{~m}\right)$ curves are situated below the double fine line help in the safe obstacle avoidance, i.e., they indicate the trajectory planning methods and the range of the $L_{a}$ values that meet the $\mathrm{Cb}$ sub-criterion (see Table 2) regarding the stability of growth in $y_{C B}(x)$ during the obstacle avoidance manoeuvre.

- $\quad$ Figure 17B shows the $\left|\alpha_{B E k s t r}\left(L_{a}\right)\right|$ curves, representing the absolute value of the tyre sideslip angle $\alpha_{B}(x)$. The double fine line shows the limit value of $|\alpha|<16 \mathrm{deg}$. The curves below the double fine line show the alternatives that meet the $\mathrm{Cb}$ sub-criterion, i.e., all the alternatives of the $L_{a}$ values at $v=40 \mathrm{~km} / \mathrm{h}$; for $v=60 \mathrm{~km} / \mathrm{h}$ and $80 \mathrm{~km} / \mathrm{h}$, however, the $\mathrm{Cb}$ sub-criterion is only met for a few $L_{a}$ values and providing that the cosine method is used for planning the $y_{M}(x)$ trajectory. 
- $\quad$ Figure $17 \mathrm{C}-\mathrm{E}$ show the $y_{K B}\left(L_{a}\right)$ curves, representing the clearance between edge $K$ and trailer corners (corners $N_{F R B}$ and $N_{R R B}$ ) at the instant when the obstacle is passed by. The safe obstacle avoidance is only possible (i.e., the B criterion, see Table 2, is met) for the alternatives for which the $y_{K B}$ values obtained fall between the double fine lines $\left(y_{K B} \in(0 ; 2 \mathrm{~m})\right)$. Such a result was achieved e.g., for $v=60 \mathrm{~km} / \mathrm{h}$ and $L_{a} \geq 7 \mathrm{~m}$ in the cosine method, while in other methods, the $N_{R R B}$ corner goes beyond the area of the lane available. For $v=80 \mathrm{~km} / \mathrm{h}$, the CT unit will hit the obstacle, regardless of the trajectory planning method used.

Table 2. Connection between the values given in individual columns of Table 1 and the procedure described above.

\begin{tabular}{ccccccc}
\hline Columns of Table 1 & 5 & $\mathbf{6 - 7}$ & $\mathbf{8 - 1 0}$ & $\mathbf{1 1 - 1 3}$ & $\mathbf{1 4}$ & $\mathbf{1 5 - 1 6}$ \\
\hline $\begin{array}{c}\text { Criteria and sub-criteria used in } \\
\text { the procedure that are relevant to } \\
\text { the values in specific columns }\end{array}$ & $\mathrm{Cb}$ & $\mathrm{A} ; \mathrm{B}$ & $\mathrm{Cb}$ & $\mathrm{B}$ & $\mathrm{B}$ & $\mathrm{Ca}$ \\
\hline
\end{tabular}

The results obtained for individual solution alternatives, exemplified in Table 1 and Figure 17, facilitated the use of the procedure presented. The procedure enabled the following decisions to be effectively made about the temporary solutions implemented in the control system for the distance $x_{0}$ of the CT unit approaching the obstacle:

- the trajectory planning method will be based on the cosine function;

- $\quad$ the optimum anticipation radius will be $L_{a}=6 \mathrm{~m}$.

\section{Analysis of the Motion of a CT Unit When Avoiding an Obstacle}

At the next step, the CT unit's motion was analyzed with taking into account the temporary decisions made in Section 6. The cosine function was adopted as a basis for the method of planning the vehicle trajectory for the distance travelled by the CT unit when approaching the obstacle; the anticipation radius value was assumed as $L_{a}=6 \mathrm{~m}$. For such assumptions, recommendations were worked out regarding the clearance margin value $y_{W}$ necessary to plan a trajectory that would ensure safe avoidance of the obstacle. The area of searching for the $y_{W}$ values is limited by the available space in the carriageway $\left(R_{\max }\right.$ and $y_{0}$, see Figure 1). In the critical situation under analysis, the $y_{W}$ value may be within a range of $0-2 \mathrm{~m}$.

In consideration of the above, model tests were carried out for various values of clearance margin $y_{W}$ and CT unit's speed $v$. The results of these tests made a basis for recommending the favorable $y_{W}$ values.

\subsection{Impact of Vehicle Speed on the Obstacle Avoidance Process}

The vehicle speed is an effect of control system's decision made within following the general strategy of CT unit's motion. Figure 18 shows simulation results obtained for $v=50 \mathrm{~km} / \mathrm{h}, 60 \mathrm{~km} / \mathrm{h}$, and $70 \mathrm{~km} / \mathrm{h}$.

The simulation was carried out while observing, in particular, the behavior of the CT unit driven on dry road surface to follow a trajectory $y_{M}(x)$ calculated for a clearance margin of $y_{W}=0.5 \mathrm{~m}$. The applying of rising vehicle speed values as an input caused:

- $\quad$ increasing departure of trajectories $y_{C A}(x)$ and $y_{C B}(x)$ from trajectory $y_{M}(x)$, which can be seen in the animation (Figure 18A) and in Figure 18B;

- growing motorcar yaw $\psi_{A}$ which helps to avoid a collision with the obstacle at $v=50 \mathrm{~km} / \mathrm{h}$ (see the $\psi_{A}$ curves in Figure 18A,C), but becomes hazardous at $v=70 \mathrm{~km} / \mathrm{h}$; similarly, the trailer yaw angle rose as well (see the $\psi_{B}$ curve in Figure 18C);

- $\quad$ necessity to increase the steering wheel angle (Figure 18C); within the distance $x_{0}$, two extremums occurred in this angle and the span between them grew from $\Delta \delta_{H}=134 \mathrm{deg}$ at $v=50 \mathrm{~km} / \mathrm{h}$ to $\Delta \delta_{H}=370.7 \mathrm{deg}$ at $v=70 \mathrm{~km} / \mathrm{h}$; 
- growing span between the extreme values of the $\delta_{H}$ angle, which resulted in high lateral acceleration values, from $a_{y E k s t r}=3.4-3.8 \mathrm{~m} / \mathrm{s}^{2}$ at $v=50 \mathrm{~km} / \mathrm{h}$ to $4.7-6.7 \mathrm{~m} / \mathrm{s}^{2}$ at $v=60-70 \mathrm{~km} / \mathrm{h}$ on dry road surface (Figure 18E); the acceleration values for the trailer exceeded those for the towing vehicle by $12-22 \%$;

- $\quad$ rising extreme values of the tyre sideslip angles (for the rear axle wheels of the motorcar and the trailer axle wheels), from $3 \mathrm{deg}$ at $v=50 \mathrm{~km} / \mathrm{h}$ to $11 \mathrm{deg}$ at $v=70 \mathrm{~km} / \mathrm{h}$ (Figure 18D); the extreme values of the tire sideslip angle of the trailer wheels exceeded those of the motorcar's rear axle wheels by $7-30 \%$ (this trailer's predominance grew with rising vehicle speeds).

A
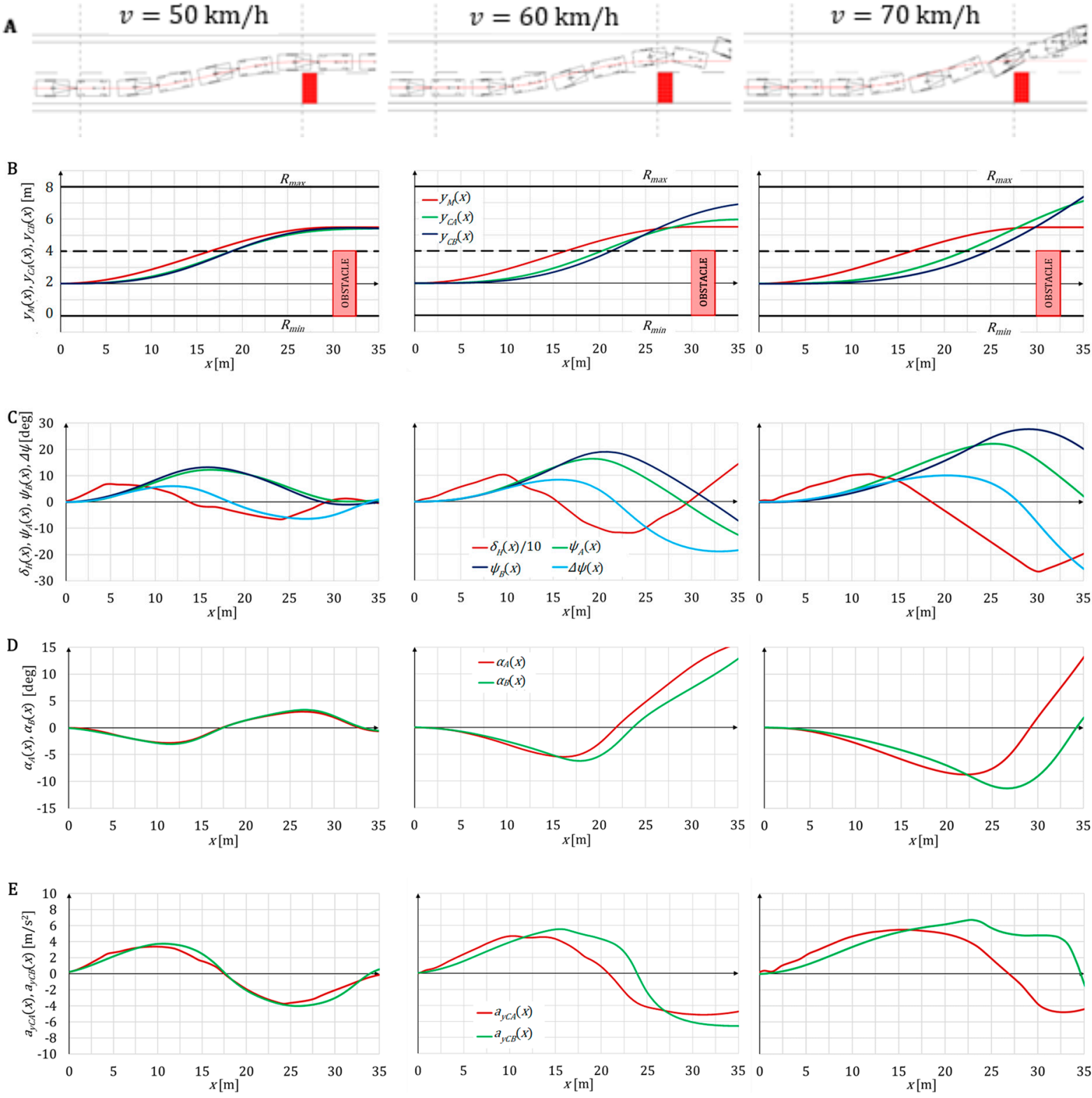

Figure 18. Obstacle avoidance simulation results obtained for the cosine method, $L_{a}=6 \mathrm{~m}, y_{W}=0.5 \mathrm{~m}$, dry road surface and different driving speeds (individual columns): (A) CT unit's motion animation; (B) path planning trajectory $y_{M}(x)$ and vehicles center of mass trajectory $y_{C_{s}}(x) ;(\mathbf{C})$ steering wheel angle $\delta_{H}(x)$, yaw angle $\psi_{A}(x)$, trailer drawbar turning angle $\Delta \psi(x) ;(\mathbf{D})$ tire sideslip angles for the rear axle of vehicles $\alpha_{s}(x) ;(\mathbf{E})$ lateral acceleration of vehicles center of mass $a_{y C_{s}}(x)$.

The above shows that the higher vehicle speed, the more attention should be paid to the clearance margin values within $y_{W}<0.5 \mathrm{~m}$ when searching for the trajectory. If this is 
done, the trajectory curvature as well as the $a_{y}$ values will be reduced. In consequence, the centrifugal force and the angle $\psi_{A}$ of yaw of the car (and of the trailer, too) in the dangerous direction will decrease (Figure 18A). The risk of unstable trailer's motion resulting from high yaw angle values $\psi_{A}$ and $\psi_{B}$ has been confirmed by the research reported in [15]. Therefore, the lowering of the $y_{W}$ values when planning the trajectory $y_{M}(x)$ may produce advantageous solutions.

\subsection{Impact of the Clearance Margin $y_{W}$ on the Safety of Obstacle Avoidance}

The simulation results presented in Figures 19-21 have been obtained for clearance margin values $y_{W}=0-2.0 \mathrm{~m}$ and for the CT unit being driven on dry and wet road surface with a speed of $v=40-90 \mathrm{~km} / \mathrm{h}$. This has made it possible to formulate a more detailed recommendation for the selection of $y_{W}$.

A

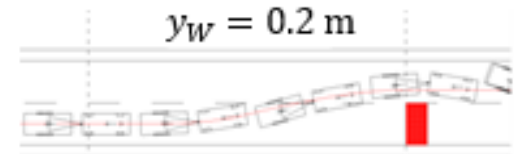

B
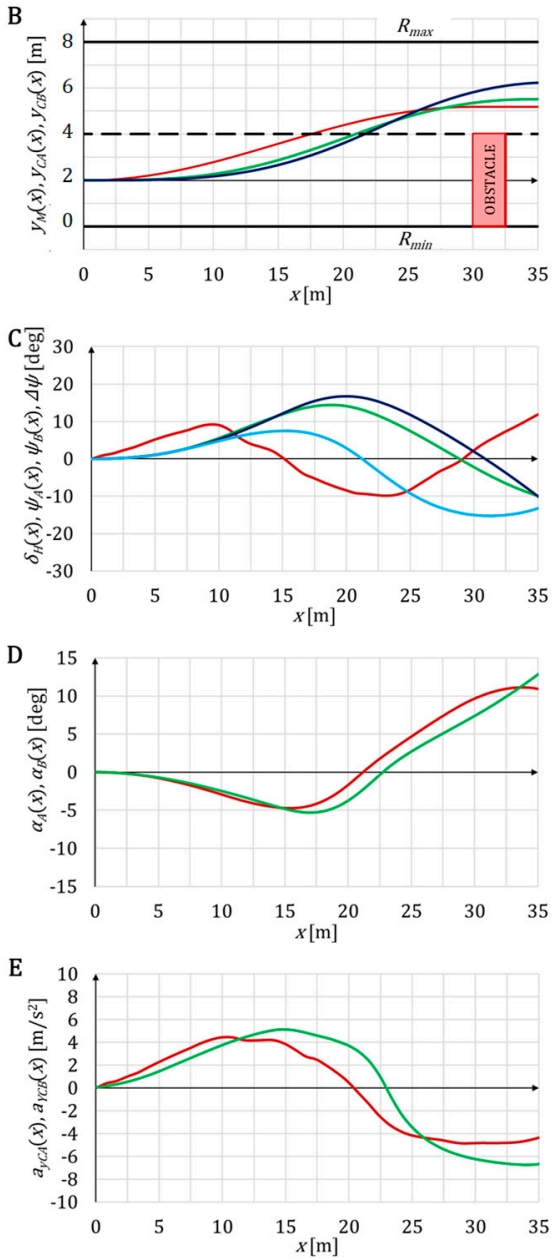

$y_{W}=0.5 \mathrm{~m}$
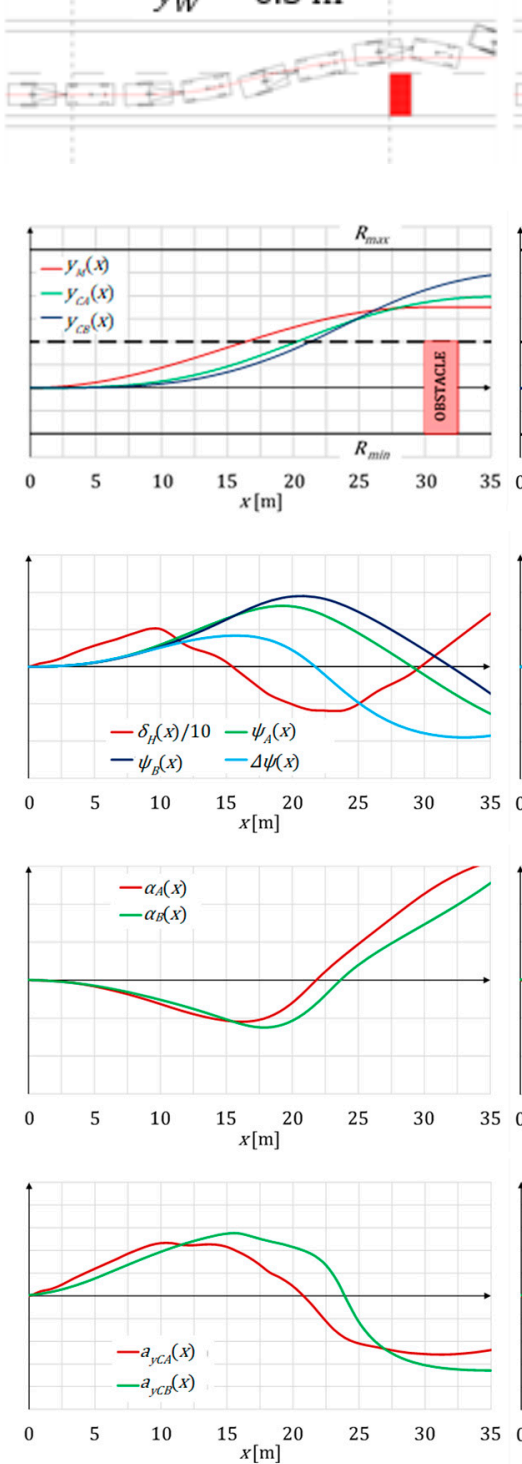
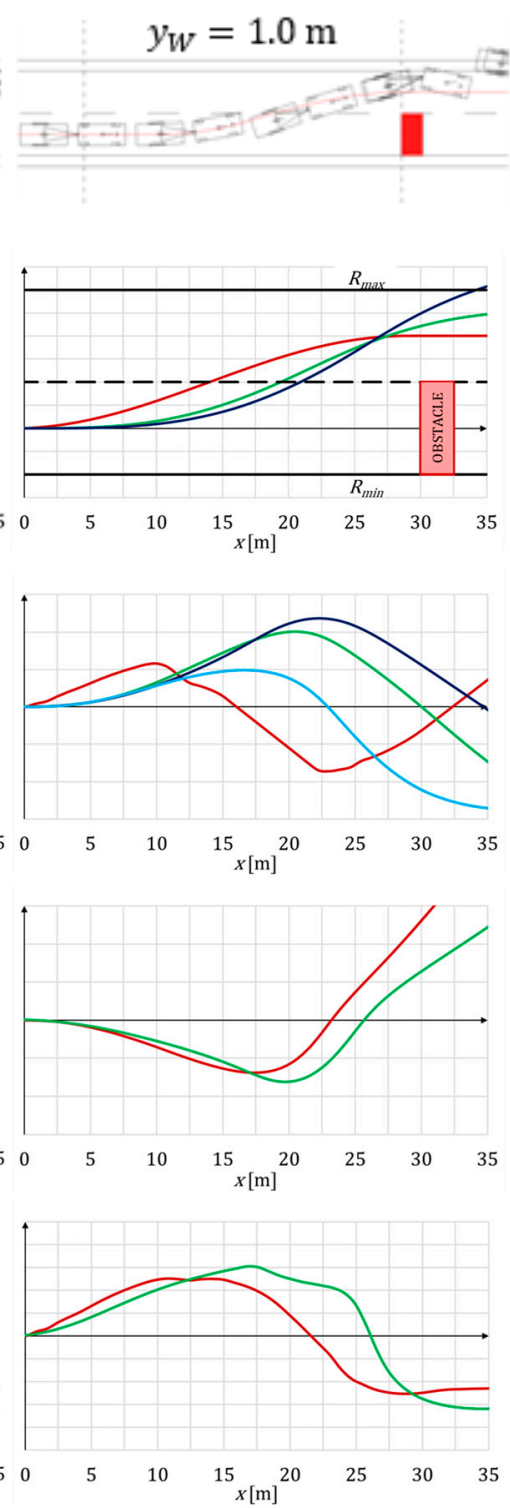

Figure 19. Curves representing selected physical quantities for the cosine trajectory planning method, $L_{a}=6 \mathrm{~m}$, $v=60 \mathrm{~km} / \mathrm{h}$, dry road surface, and three clearance margin values $y_{W}$ (individual columns): (A) CT unit's motion animation; (B) path planning trajectory $y_{M}(x)$ and vehicles center of mass trajectory $y_{C S}(x)$; (C) steering wheel angle $\delta_{H}(x)$, yaw angle $\psi_{A}(x)$, trailer drawbar turning angle $\Delta \psi(x) ;\left(\right.$ D) tire sideslip angles for the rear axle of vehicles $\alpha_{s}(x) ;($ E) lateral acceleration of vehicles center of mass $a_{y C s}(x)$. 

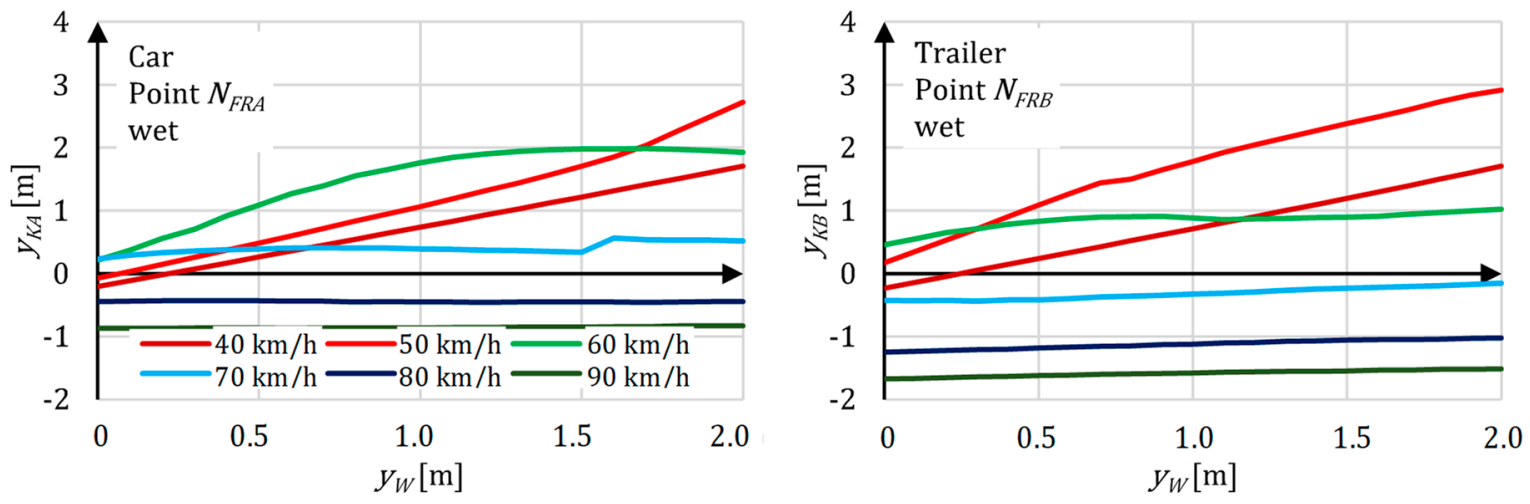

Figure 20. Distance $y_{K}$ between the front corner of the car and trailer $\left(N_{F R A}, N_{F R B}\right)$ and the obstacle when the latter was passed by wet road surface, $y_{W}=0.0-2.0 \mathrm{~m}$.
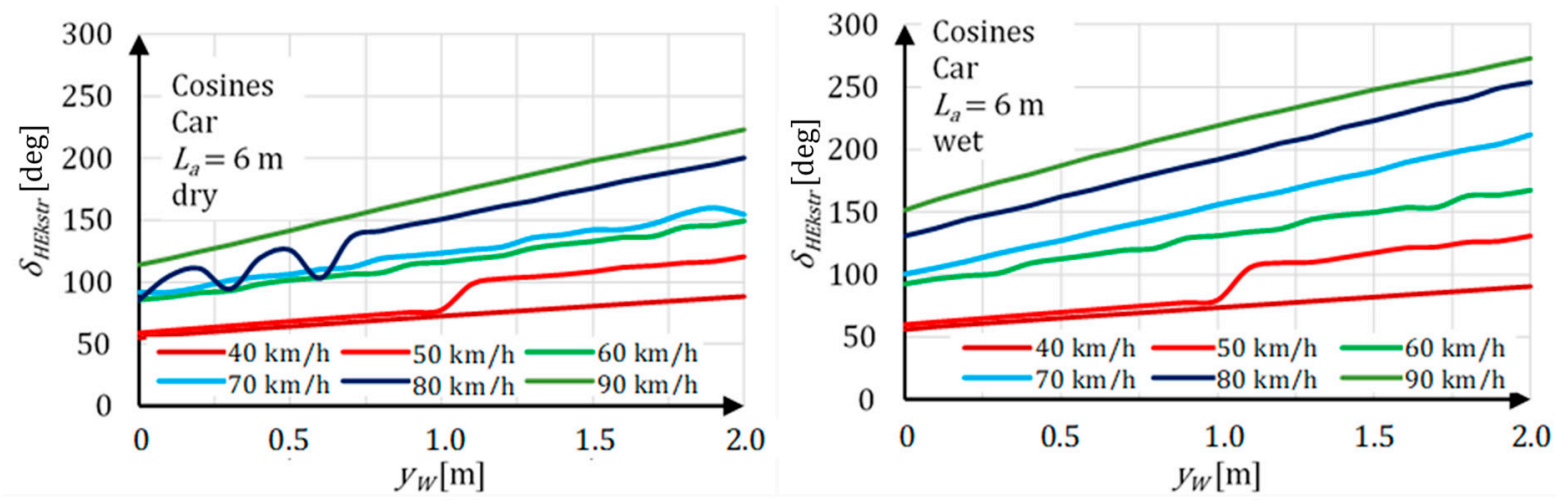

Figure 21. Extreme values of the steering wheel angle (the first extremum of the $\delta_{H}(x)$ curve) vs. the clearance margin $y_{W}$ for vehicle speeds of $v=40-90 \mathrm{~km} / \mathrm{h}$.

Figure 19 presents the process of obstacle avoidance by a CT unit moving with a speed of $v=60 \mathrm{~km} / \mathrm{h}$, with the trajectory $y_{M}(x)$ having been calculated for $y_{W}=0.2 \mathrm{~m}, 0.5 \mathrm{~m}$, and $1.0 \mathrm{~m}$. The results of these simulations provide grounds for a statement that when the clearance margin value $y_{W}$ was reduced from $1.0 \mathrm{~m}$ to $0.2 \mathrm{~m}$, then:

- curvature of trajectory $y_{M}(x)$ and departure of trajectories $y_{C A}(x)$ and $y_{C B}(x)$ from trajectory $y_{M}(x)$ decreased by $38-40 \%$, which can be seen in Figure 19B;

- clearances $y_{K A}$ and $y_{K B}$ decreased from $1.5 \mathrm{~m}$ to $0.3 \mathrm{~m}$ and from $1.9 \mathrm{~m}$ to $1.1 \mathrm{~m}$, respectively (Figure 19A);

- $\quad$ extreme values of the steering wheel angle were reduced and the span $\Delta \delta_{h}$ between them, observed within the $x_{0}$ road section, dropped from 287.9 deg to $190.7 \mathrm{deg}$; trailer drawbar turning angle $\Delta \psi$ at the instant when the obstacle was being passed by dropped from $10.7 \mathrm{deg}$ to $3.6 \mathrm{deg}$;

- lateral accelerations of the towing vehicle and the trailer, $a_{y C A}$ and $a_{y C B}$, observed within the $x_{0}$ road section, declined from $5.0-6.1 \mathrm{~m} / \mathrm{s}^{2}$ to $4.4-5.1 \mathrm{~m} / \mathrm{s}^{2}$, respectively;

- motorcar tire sideslip angle $\alpha_{A}$ at the instant when the obstacle was being passed by declined from $13.8 \mathrm{deg}$ to $10.0 \mathrm{deg}$.

It should be added here that when the clearance margin value was raised within the range $y_{W}>0.5 \mathrm{~m}$ in the vehicle driving conditions under analysis, then:

- at the instant when the obstacle was being passed by, the tire sideslip angle of the motorcar rear axle wheels rose from $10.0 \mathrm{deg}$ to $13.8 \mathrm{deg}$, i.e., it reached values that made it difficult to control the vehicle movement (cf. the $F_{y}(\alpha)$ curve in Figure 8); 
- the differences between the trajectories $\left(y_{C B}(x)-y_{C A}(x)\right)$ and the yaw angles $\left(\psi_{B}(x)-\psi_{A}(x)\right)$ of the trailer and the car increased as well, which may result in the instability of the CT unit's motion on the road section just beyond the obstacle.

The tests represented in Figure 19 have confirmed that the applying of low $y_{W}$ values when planning the obstacle-avoiding trajectory would be well justified, but within a limited range of vehicle speeds (especially on wet road surface). This information was gained after the tests were extended to a vehicle speed range of $v=40-90 \mathrm{~km} / \mathrm{h}$.

In Figure 20, simulation results have been presented in the form of curves $y_{K}=f\left(y_{W}\right)$ plotted for the obstacle avoidance on wet road surface. When analyzing these results, it should be taken into account that the $y_{K}$ values should be higher than zero, preferably within the range of $0-2 \mathrm{~m}$, for the obstacle avoidance to be safe. The course of the green curve in Figure 20 confirms the conclusions drawn from the tests presented in Figure 19 for $v=60 \mathrm{~km} / \mathrm{h}$. For such a vehicle speed, the $y_{W}$ values may be chosen from a wide range; previously, the recommendable value was specified as $y_{W} \cong 0.2 \mathrm{~m}$ for dry road surface.

The angle $\delta_{H}(t)$ corresponds to a signal generated by the control system (Figure 3). Its values at the first extremum have been shown in Figure 21. During the initial part of the obstacle avoidance maneuver $\left(x \in\left(0 ; 0.5 x_{0}>\right)\right.$, they should steeply rise so that the CT unit would be able to follow the path with the curvature as planned. Such an effect may be obtained if a big distance margin $y_{W}$ is adopted. With this objective in view, high clearance margin values should be used when planning the trajectory $y_{M}(x)$. However, it is not easy to make the CT unit avoid the obstacle this way at as low speeds as $v>60 \mathrm{~km} / \mathrm{h}$ because of high values of lateral acceleration $a_{y}$, lateral force $F_{Q}$, and tire sideslip (Figures 18D and 19D), which increase the distances between the vehicle paths $\left(y_{C A}(x)\right.$ and $\left.y_{C B}(x)\right)$ and the trajectory planned $\left(y_{M}(x)\right)$ (Figure $21 \mathrm{~B}$ for $v=70 \mathrm{~km} / \mathrm{h}$ ). This highlights one more of the dilemmas to be resolved when selecting the $y_{W}$ values.

A synthetic summary of the simulation results presented in Figures 19-21 has made it possible to formulate some recommendations for the selection of $y_{W}$; simultaneously, it has highlighted the following dilemmas:

- It is recommendable to apply low $y_{W}$ values because the trajectories thus planned do not require too high extreme values of the steering wheel angle and do not result in excessive values of lateral vehicle accelerations and tire sideslip angles; thanks to this, the vehicle path may run relatively close to $y_{M}(x)$.

- The application of high $y_{W}$ values produces high $\delta_{H}(t)$ angle values even in the initial phase of the obstacle-avoiding process $\left(x \in\left(0 ; 0.5 \mathrm{x}_{0}\right\rangle\right)$ and results in the planning of a trajectory that is characterized by big lateral displacements $y_{C A}(x)$ and $y_{C B}(x)$, especially at $v<60 \mathrm{~km} / \mathrm{h}$.

- High trajectory curvature at $v>60 \mathrm{~km} / \mathrm{h}$ generates high values of lateral acceleration $a_{y}$ and tire sideslip $\alpha$, which may make it difficult for the $\mathrm{CT}$ unit to avoid the obstacle on the second part of the $x_{0}$ road section, i.e., where $x \in\left(0.5 x_{0} ; x_{0}\right\rangle$ (Figures 19 and 21).

- The control system generates higher extreme values $\delta_{H E k s t r}$ on wet road surface than it does on dry road surface at identical $y_{W}$ values. This causes a growth in the vehicle yaw angles $\psi_{A}$ and $\psi_{B}$; high values of these angles make obstacle avoidance more difficult.

- On the wet road surface, the advantageous $y_{W}$ values are lower than those recommendable for the dry road surface; on the other hand, the range from within they may be picked is narrower than that acceptable in the latter case.

- At $v=80-90 \mathrm{~km} / \mathrm{h}$, the $y_{W}$ values under consideration do not offer a possibility of planning a trajectory that would ensure safe obstacle avoidance on wet road surface.

The very diverse impact of $y_{W}$ on the obstacle avoidance by a CT unit will be made use of to build a set of clearance margin values recommendable for the planning of an obstacle-avoiding trajectory $y_{M}(x)$. 


\section{Selection of a Clearance Margin $y_{W}$ for the Obstacle Avoidance Maneuver}

The results of an assessment carried out according to the procedure prepared as described in Section 6 became a basis for selecting temporary parameters, i.e., a method of planning the trajectory $y_{M}(x)$ and determining the value of $L_{a}$ for the critical situation under consideration. After the temporary parameters are determined as described above, a trajectory $y_{M}(x)$ is planned in the control system for a safe vehicle path to be obtained. The course of this path and the behavior of the vehicles moving along this path strongly depend on the dynamic characteristics of the CT unit, including the forces acting on the vehicles. In the critical situation under consideration, it is difficult to predict the values of such forces and the effects of their action (tire sideslip, skidding of wheels of individual axles, vehicles' yaw angles from the carriageway centerline, etc.). In such a situation, it is good to have a set of the $y_{W}$ values that would facilitate the planning of a safe trajectory. The description provided in Section 2 and Figure 1 shows that the clearance margin in the critical situation under analysis should be within a range of $y_{W} \in(0,2 \mathrm{~m})$. Such a margin makes it possible to reserve a corridor for the CT unit's motion, wider than the CT unit width $b$. The said corridor is necessary because the vehicles move in positions yawed by angles $\psi_{A}$ and $\psi_{B}$ from the carriageway centreline when they are avoiding the obstacle. This yaw can be seen in Figures 14 and 15 .

In the simulation tests carried out, various alternatives of the obstacle avoidance process were analyzed. To assess the alternatives, the distances $y_{K A}$ and $y_{K B}$ between the edge (corner) of the obstacle and the side of the car and the trailer when passing by the obstacle were taken as a basis. The test result is considered successful if, during the obstacle-avoiding phase of the maneuver, the CT unit safely passed by the obstacle and stayed within the lane planned also just beyond the obstacle, i.e., within the road section $x \in\left(x_{0} ; x_{0}+10 \mathrm{~m}\right\rangle$ (cf. Table 1$)$. When selecting the $y_{W}$ (clearance margin) values for the trajectory planning, the following results were considered satisfactory:

- $\quad$ safe obstacle avoidance, i.e., none of the points within CT unit came into contact with the obstacle or left the lane planned;

- $\quad$ obstacle avoidance using the road shoulder.

If a collision took place between the CT unit and the obstacle contour or the CT unit found itself outside of the road (i.e., outside of the carriageway and the road shoulder) or overturned, such a test result was considered as a "collision with the obstacle" or maneuver failure. The test results have been presented in a synthetic form in Figures 22 and 23 and the clearance margin $\left(y_{W}\right)$ values used to plan the safe trajectory $y_{M}(x)$ are specified in Table 3.


Figure 22. Area of choosing the $y_{W}$ values when planning a vehicle trajectory for safe obstacle avoidance on dry road surface; motorcar and trailer. 

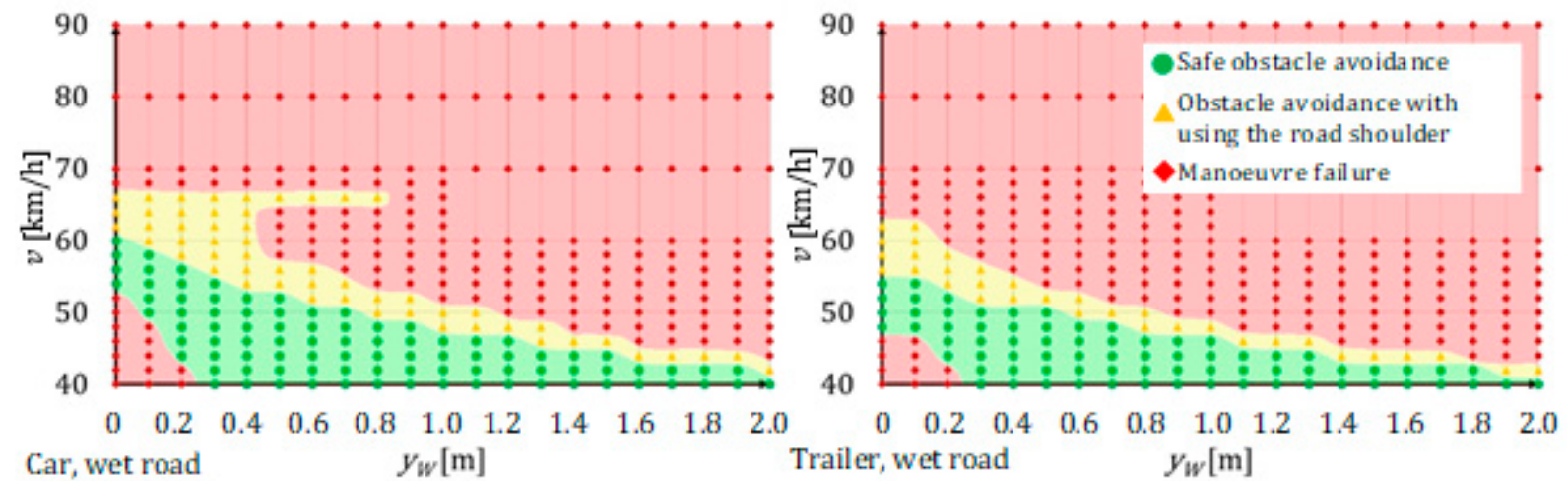

Figure 23. Area of choosing the $y_{W}$ values when planning a vehicle trajectory for safe obstacle avoidance on wet road surface; motorcar and trailer.

Table 3. Possibilities of safe avoidance of the obstacle.

\begin{tabular}{|c|c|c|c|c|c|}
\hline \multirow[t]{2}{*}{ Road Surface } & \multirow[t]{2}{*}{$v[\mathrm{~km} / \mathrm{h}]$} & \multicolumn{2}{|c|}{$\begin{array}{c}y_{W}[\mathrm{~m}] \text { for Planning a Trajectory that Would } \\
\text { Ensure Safe Obstacle Avoidance }\end{array}$} & \multicolumn{2}{|c|}{$\begin{array}{c}y_{W}[\mathrm{~m}] \text { for Planning a Trajectory that Would } \\
\text { Ensure Safe Obstacle Avoidance with Using } \\
\text { the Road Shoulder }\end{array}$} \\
\hline & & $\begin{array}{l}\text { Motorcar as a Part } \\
\text { of the CT Unit }\end{array}$ & CT Unit as a Whole & $\begin{array}{l}\text { Motorcar as a Part } \\
\text { of the CT Unit }\end{array}$ & CT Unit as a Whole \\
\hline \multirow{8}{*}{ dry } & 40 & $0.3-2.0$ & $0.3-2.0$ & $0.3-2.0$ & $0.3-2.0$ \\
\hline & 50 & $0.2-1.7$ & $0.2-1.4$ & $0.2-2.0$ & $0.2-1.9$ \\
\hline & 60 & $0.0-0.6$ & $0.0-0.2$ & $0.0-0.9$ & $0.0-0.5$ \\
\hline & 62 & $0.0-0.4$ & 0.0 & $0.0-0.7$ & $0.0-0.4$ \\
\hline & 66 & $0.0-0.1$ & - & $0.0-0.4$ & $0.0-0.1$ \\
\hline & 68 & 0.0 & - & $0.1-0.3$ & 0.0 \\
\hline & 70 & - & - & $0.0-0.2$ & - \\
\hline & 80 & - & - & $0.0-0.2$ & - \\
\hline \multirow{6}{*}{ wet } & 40 & $0.3-2.0$ & $0.3-2.0$ & $0.3-2.0$ & $0.3-2.0$ \\
\hline & 50 & $0.1-0.7$ & $0.0-0.5$ & $0.1-1.1$ & $0.0-0.8$ \\
\hline & 60 & 0.0 & - & $0.0-0.4$ & $0.0-0.1$ \\
\hline & 62 & - & - & $0.0-0.4$ & $0.0-0.1$ \\
\hline & 66 & - & - & $0.0-0.8$ & - \\
\hline & 70 & - & - & - & - \\
\hline
\end{tabular}

The area of acceptable selection of the $y_{W}$ values, as plotted in Figure 22, shows that a motorcar in a CT unit moving on dry road surface would be able to avoid the obstacle even if travelling with a speed of up to $v=68 \mathrm{~km} / \mathrm{h}$, while the trailer towed by it would safely avoid the obstacle only if its speed did not exceed $v=62 \mathrm{~km} / \mathrm{h}$. If the road surface is wet (see Figure 23), a safe obstacle avoidance would only be possible if the CT unit's speed were limited to $v=54 \mathrm{~km} / \mathrm{h}$. Assuming the acceptability of using the road shoulder (up to $1 \mathrm{~m}$ wide) in the critical situation, the obstacle would be avoided if the vehicle speed were up to $68 \mathrm{~km} / \mathrm{h}$ on dry road surface and up to $62 \mathrm{~km} / \mathrm{h}$ on the wet road surface (see Table 3).

The tests described have shown the narrowness of the area of selection of the $y_{W}$ values that would enable safe obstacle avoidance in the critical situation under consideration. 


\section{Summary}

This study is dedicated to a critical (pre-accident or causing a collision hazard) road situation where immediate counteraction of the vehicle control system is required in a space that has been only partly defined. The hazards accompanying such a situation arise from the short time available for the reaction and from the complexity of the interactions taking place between the motorcar, trailer, controller, and road surface. The said interactions are strongly non-linear. In the study, an assumption has been made that the information received from the environment perception system will cause the settings of the control system of the CT unit to be re-adjusted as appropriate. The new settings will be introduced temporarily, for the time of passing by the obstacle, and their values will differ from those required at the stable vehicle drive before and after the obstacle avoidance maneuver.

In consideration of the above, the following was worked out:

- models of dynamics of a CT unit and of its control system;

- procedure of selection of the temporary system settings, i.e., a method of planning the trajectory $y_{M}(x)$ and the value of the anticipation radius $L_{a}$ for the time of the critical situation;

- rudiments of selecting the value of the variable parameter, i.e., the clearance margin $y_{W}$.

Based on the above, tests were carried out to select the control system parameters (temporary and variable) that would be appropriate for the specific difficult road situation. The impact of the method of planning the trajectory $y_{M}(x)$ and the value of the anticipation radius $L_{a}$ in the control system on the feasibility of safe avoidance of an obstacle having suddenly appeared has been examined. In consideration of high curvatures of the trajectories planned, high vehicle speeds, and dynamic action of the trailer, particular attention was paid to the impact of tire slip and skidding on vehicles' behavior when moving along the curvilinear path.

The research carried out has made it possible to formulate the following findings and conclusions for the CT unit's control system operating in the critical situation under analysis:

- The cosine method used to plan a trajectory $y_{M}(x)$ produced better performance of the obstacle avoidance maneuver in comparison with the other methods taken into account.

- The anticipation radius value at which the obstacle avoidance maneuver was most effective was $L_{a}=6 \mathrm{~m}$.

- The area of selection of the $y_{W}$ values for planning the vehicle trajectory for the obstacle avoidance time was narrow (Figures 22 and 23) and the narrower, the higher the vehicle speed was.

- The impact of growth in the driving speed on CT unit's behaviour during obstacle avoidance was not definite, because, e.g., small motorcar yaw angle values $\psi_{A}$ helped to avoid a collision with the obstacle at $v=50 \mathrm{~km} / \mathrm{h}$ and $60 \mathrm{~km} / \mathrm{h}$ (see the $\psi_{A}$ curves in Figure 18A,C) but became hazardous at $v=70 \mathrm{~km} / \mathrm{h}$.

- When a safe obstacle avoidance trajectory is planned for a speed exceeding $60 \mathrm{~km} / \mathrm{h}$, low clearance margin $\left(\psi_{A}\right)$ values are required, i.e., the trajectory should be very close to the obstacle.

Results of the research being carried out support the current trends in the construction of vehicle control algorithms, where the definition of rigid operation rules is being abandoned in favor of immediate and ongoing shaping of the properties and areas of suitable solutions. This is of significant importance for rare critical situations. In such cases, the temporary data obtained from previous computer simulations and stored in the system controller are chiefly used. 
Author Contributions: Conceptualization, L.P., P.S. and M.Z.; methodology, L.P. and M.Z.; software, P.S.; validation, T.P. and P.S.; formal analysis, L.P., M.Z., P.S.; investigation, L.P., M.Z. and P.S.; resources, T.P.; data curation, P.S.; writing-original draft preparation, L.P.; writing-review and editing, M.Z., P.S., M.G., T.P. and T.L.S.; visualization, M.Z., L.P. and P.S.; supervision, L.P.; project administration, M.Z.; funding acquisition, M.G. All authors have read and agreed to the published version of the manuscript.

Funding: This research received no external funding.

Conflicts of Interest: The authors declare no conflict of interest.

\section{References}

1. Katrakazas, C.; Quddus, M.; Chen, W.H.; Deka, L. Real-time motion planning methods for autonomous on-road driving: State-of-the-art and future research directions. Transp. Res. Part C 2015, 60, 416-442. [CrossRef]

2. Prochowski, L.; Ziubiński, M.; Szwajkowski, P.; Pusty, T.; Gidlewski, M. Experimental and Simulation Examination of the Impact of the Control Model on the Motion of A Motorcar with A Trailer in A Critical Situation. In Proceedings of the 15th International Conference Dynamical Systems-Theory and Applications DSTA, Łódź, Poland, 2-5 December 2019; pp. 409-422. [CrossRef]

3. Wu, B.; Zhu, X.; Shen, J.; Cang, X. Analysis of Steering Model for Emergency Lane Change Based on the China Naturalistic Driving Data. In Proceedings of the SAE World Congress Experience (WCX), Detroit, MI, USA, 4-6 April 2017. [CrossRef]

4. Jurecki, R.S.; Stańczyk, T.L. Driver model for the analysis of pre-accident situations. Veh. Syst. Dyn. 2009, 47, 589-612. [CrossRef]

5. Sun, C.; Zhang, X.; Xi, L.; Tian, Y. Design of a path-tracking steering controller for autonomous vehicles. Energies 2018, 11, 1451. [CrossRef]

6. Wang, P.; Gao, S.; Li, L.; Sun, B.; Cheng, S. Obstacle avoidance path planning design for autonomous driving vehicles based on an improved artificial potential field algorithm. Energies 2019, 12, 2342. [CrossRef]

7. Fényes, D.; Németh, B.; Gáspár, P. A Novel Data-Driven Modeling and Control Design Method for Autonomous Vehicles. Energies 2021, 14, 517. [CrossRef]

8. Moshchuk, N.; Chen, S.K.; Zagorski, C.; Chatterjee, A. Path planning for collision avoidance maneuver, in ASME 2013 International Mechanical Engineering Congress and Exposition. Am. Soc. Mech. Eng. Digit. Collect. 2013, 56420, V013T14A016. [CrossRef]

9. Korzeniowski, D.; Ślaski, G. Method of planning a reference trajectory of a single lane change manoeuver with Bezier curve. In IOP Conference Series: Materials Science and Engineering; IOP Publishing: Bristol, UK, 2016. [CrossRef]

10. Anderson, S.J.; Peters, S.C.; Pilutti, T.E.; Iagnemma, K. An optimal-control-based framework for trajectory planning, threat assessment, and semi-autonomous control of passenger vehicles in hazard avoidance scenarios. Int. J. Veh. Auton. Syst. 2010, 8, 190-216. [CrossRef]

11. Snider, J.M. Automatic Steering Methods for Autonomous Automobile Path Tracking; CMU-RITR-09-08; Robotics Institute: Pittsburgh, PA, USA, 2009.

12. Hu, X.; Chen, L.; Tang, B.; Cao, D.; He, D. Dynamic path planning for autonomous driving on various roads with avoidance of static and moving obstacles. Mech. Syst. Signal Process. 2018, 100, 482-500. [CrossRef]

13. Zanchetta, M.; Tavernini, D.; Sorniotti, A.; Gruber, P.; Lenzo, B.; Ferrara, A.; de Nijs, W. Trailer control through vehicle yaw moment control: Theoretical analysis and experimental assessment. Mechatronics 2019, 64, 102282. [CrossRef]

14. Hac, A.; Fulk, D.; Chen, H. Stability and control considerations of vehicle-trailer combination. SAE Int. J. Passeng. Cars-Mech. Syst. 2008, 1, 925-937. [CrossRef]

15. Plöchl, M.; Lugner, P. Passenger car and passenger car-trailer-Different tasks for the driver. JSAE Rev. 1999, 20, 543-548. [CrossRef]

16. Darling, J.; Tilley, D.; Gao, B. An experimental investigation of car-trailer high-speed stability. Proc. Inst. Mech. Eng. Part D 2009, 223, 471-484. [CrossRef]

17. Balal, E.; Cheu, R.L.; Sarkodie-Gyan, T. A binary decision model for discretionary lane changing move based on fuzzy inference system. Transp. Res. Part C 2016, 67, 47-61. [CrossRef]

18. Chen, G.; Zhang, W.G.; Zhang, X.N. Fuzzy neural control for unmanned robot applied to automotive test. Ind. Robot 2013, 40, 450-461. [CrossRef]

19. Ivanov, V. A review of fuzzy methods in automotive engineering applications. Eur. Transp. Res. Rev. 2015, 7, 29. [CrossRef]

20. Khalaji, A.K. PID-based target tracking control of a tractor-trailer mobile robot. Proc. Inst. Mech. Eng. Part C 2019, $233,4776-4787$. [CrossRef]

21. Yue, M.; Hou, X.; Gao, R.; Chen, J. Trajectory tracking control for tractor-trailer vehicles: A coordinated control approach. Nonlinear Dyn. 2018, 91, 1061-1074. [CrossRef]

22. Ni, J.; Hu, J. Dynamics control of autonomous vehicle at driving limits and experiment on an autonomous formula racing car. Mech. Syst. Signal Process. 2017, 90, 154-174. [CrossRef]

23. Taghavifar, H.; Rakheja, S. Path-tracking of autonomous vehicles using a novel adaptive robust exponential-like-sliding-mode fuzzy type-2 neural network controller. Mech. Syst. Signal Process. 2019, 130, 41-55. [CrossRef]

24. Gidlewski, M.; Jackowski, J.; Jemioł, L.; Żardecki, D. Sensitivity of a vehicle lane change control system to disturbances and measurement signal errors-Modeling and numerical investigations. Mech. Syst. Signal Process. 2021, 147, 107081. [CrossRef] 
25. Mercorelli, P. Fuzzy Based Control of a Nonholonomic Car-Like Robot for Drive Assistant Systems. In Proceedings of the 2018 19th International Carpathian Control Conference (ICCC), Szilvasvarad, Hungary, 28-31 May 2018; pp. 434-439. [CrossRef]

26. Alshaer, B.J.; Darabseh, T.T.; Alhanouti, M.A. Path planning, modeling and simulation of an autonomous articulated heavy construction machine performing a loading cycle. Appl. Math. Model. 2013, 37, 5315-5325. [CrossRef]

27. Wang, H.W.; Yu, X.C.; Song, H.B.; Lu, Z.H.; Lloret, J.; You, F. A Global Optimal Path Planning and Controller Design Algorithm for Intelligent Vehicles. Mob. Netw. Appl. 2018, 23, 1165-1178. [CrossRef]

28. Road Traffic Office. Road Traffic Accidents in Poland in 2019; Polish Police Headquarters, Road Traffic Office: Warsaw, Poland, 2020.

29. Li, X.; Sun, Z.; Cao, D.; Liu, D.; He, H. Development of a new integrated local trajectory planning and tracking control framework for autonomous ground vehicles. Mech. Syst. Signal Process. 2017, 87, 118-137. [CrossRef]

30. Demonceaux, C.; Potelle, A.; Kachi-Akkouche, D. Obstacle detection in a road scene based on motion analysis. IEEE Trans. Veh. Technol. 2004, 53, 1649-1656. [CrossRef]

31. PC-CRASH-A Simulation Program for Vehicle Accidents-Operating and Technical Manual, Version 10.0; Dr. Steffan Datentechnik: Linz, Austria, 2013.

32. Steffan, H.; Moser, A. The trailer Simulation model of PC-Crash. SAE Trans. 1998, 107, 886-896. [CrossRef]

33. Rill, G. Simulation von Kraftfahrzeugen; Vieweg \& Sohn Verlag GmbH: Braunschweig, Germany, 1994.

34. Hirschberg, W.; Rill, G.; Weinfurter, H. Tire model TMeasy. Veh. Syst. Dyn. 2007, 45, 101-119. [CrossRef]

35. Rill, G. TMeasy-A Handling Tire Model based on a three-dimensional slip approach. In Proceedings of the XXIII International Symposium on Dynamic of Vehicles on Roads and on Tracks (IAVSD 2013), Quingdao, China, 19-23 August 2013.

36. Hirschberg, W.; LČÁK, F.P.A.; Rill, G.; NÍK, J.Š.T.; Kintler, P. TMeasy for Reliable Vehicle Dynamics Simulation; SCIENTIFIC PROCEEDINGS 2009; Faculty of Mechanical Engineering, STU: Bratislava, Slovakia, 2009.

37. Rill, G. Vehicle dynamics. In Lecture Notes; Regensburg, Germany, 2009; Available online: http://pds7.egloos.com/pds/200801/1 9/01/Vehicle_Dynamics.pdf (accessed on 16 September 2020).

38. Stańczyk, T.L.; Strachowski, P. Assessment of the possibilities of determining the characteristics of a pneumatic tyre with the use of an original road test system. Arch. Automot. Eng. 2013, 59, 165-183. [CrossRef]

39. Luty, W. Tire transient properties in simulation of vehicle lateral dynamics in curvilinear motion, Prace Naukowe Politechniki Warszawskiej, Transport. Oficyna Wydawnicza Politech. Warsz. 2013, 98, 357-367.

40. ISO 3888-1:1999, Passenger Cars-Test Track for A Severe Lane-Change Manoeuvre-Part 1: Double Lane-Change; International Organization for Standardization: Geneva, Switzerland, 1999.

41. Saaty, T.L. Fundamentals of Decision Making and Priority Theory with the Analytic Hierarchy Process; RWS Publications: Pittsburgh, PA, USA, 2000.

42. Saaty, T.L.; Ozdemir, M.S. Why the magic number seven plus or minus two. Math. Comput. Model. 2003, 38, 233-244. [CrossRef]

43. Prochowski, L.; Pusty, T.; Gidlewski, M.; Jemioł, L. Experimental studies of the car-trailer system when passing by a suddenly appearing obstacle in the aspect of active safety of autonomous vehicles. In IOP Conference Series: Materials Science and Engineering; IOP Publishing: Bristol, UK, 2018; Volume 421, p. 032024. [CrossRef] 